\title{
Targeted Molecular Therapies in the Treatment of Esophageal Adenocarcinoma, Are We There Yet?
}

\author{
Shayan Khalafi ${ }^{1}$, Albert Craig Lockhart ${ }^{2,3}$, Alan S. Livingstone ${ }^{1}$ and Wael El-Rifai ${ }^{1,2,4, *}$ \\ 1 Department of Surgery, Miler School of Medicine, University of Miami, Miami, FL 33136, USA; \\ sxk1000@miami.edu (S.K.); alivings@med.miami.edu (A.S.L.) \\ 2 Department of Medicine, Miler School of Medicine, University of Miami, Miami, FL 33136, USA; \\ aclockhart@med.miami.edu \\ 3 Sylvester Comprehensive Cancer Center, Miler School of Medicine, University of Miami, \\ Miami, FL 33136, USA \\ 4 Department of Veterans Affairs, Miami Healthcare System, Miami, FL 33136, USA \\ * Correspondence: welrifai@med.miami.edu; Tel.: +1-(305)-243-9648
}

Received: 10 September 2020; Accepted: 20 October 2020; Published: 22 October 2020

check for updates

Simple Summary: Traditional therapeutic approaches to esophageal adenocarcinoma involve a combination of surgery, chemotherapy, and radiation. Despite innovations in treatment, outcomes remain poor. Targeted molecular therapies and immunotherapies have been used to great effect in various other solid tumors. Several targeted agents show promise in treating esophageal adenocarcinoma. In this review, we aim to highlight recent developments in the arena of targeted therapeutics and suggest topics of future investigations.

\begin{abstract}
Esophageal adenocarcinoma is one of the leading causes of cancer-related deaths worldwide. The incidence of esophageal adenocarcinoma has increased at an alarming rate in the Western world and long-term survival remains poor. Current treatment approaches involve a combination of surgery, chemotherapy, and radiotherapy. Unfortunately, standard first-line approaches are met with high rates of recurrence and metastasis. More recent investigations into the distinct molecular composition of these tumors have uncovered key genetic and epigenetic alterations involved in tumorigenesis and progression. These discoveries have driven the development of targeted therapeutic agents in esophageal adenocarcinoma. While many agents have been studied, therapeutics targeting the human epidermal growth factor receptor (HER2) and vascular endothelial growth factor (VEGF) pathways have demonstrated improved survival. More recent advances in immunotherapies have also demonstrated survival advantages with monoclonal antibodies targeting the programmed death ligand 1 (PD-L1). In this review we highlight recent advances of targeted therapies, specifically agents targeting receptor tyrosine kinases, small molecule kinase inhibitors, and immune checkpoint inhibitors. While targeted therapeutics and immunotherapies have significantly improved survival, the benefits are limited to patients whose tumors express biomarkers such as PD-L1 and HER2. Survival remains poor for the remainder of patients with esophageal adenocarcinoma, underscoring the critical need for development of novel treatment strategies.
\end{abstract}

Keywords: esophageal adenocarcinoma; targeted therapy; immunotherapy

\section{Introduction}

Esophageal cancer is a highly aggressive malignancy characterized by exceedingly poor survival. In 2018, there were 572,034 newly diagnosed cases of esophageal cancer worldwide, with 508,585 deaths [1]. Esophageal malignancy is primarily comprised of two distinct histological 
entities, i.e., esophageal squamous cell carcinoma (ESCC) and esophageal adenocarcinoma (EAC). Worldwide, ESCC is more prevalent while EAC dominates in Western countries. In 2020, is has been estimated that there could be 18,440 newly diagnosed cases of esophageal cancer in the United States with an estimated 16,170 deaths. The current five-year survival of esophageal cancer at any stage is $20 \%$ which has not changed significantly over the past 15 years. Five-year survival drops to approximately $5 \%$ in stage III or IV disease [2,3]. Over the past three decades, there has been a sustained increase in the incidence of EAC in many Western countries. In fact, EAC is the most rapidly increasing form of cancer in certain demographic subpopulations [4]. Males are significantly more frequently affected, and most cases occur in patients over 60 years old. This significant increase in EAC is thought to be due to the population-wide rise of its primary chronic risk factors, i.e., gastrointestinal reflux disease (GERD) and obesity [5]. The reflux of bile acids and gastric contents into the esophagus triggers a metaplastic response in the esophageal epithelium termed Barrett's esophagus (BE). The key factor defining $\mathrm{BE}$ is the replacement of the normal squamous cells lining of the esophagus with a metaplastic columnar epithelium that contains goblet cells [6]. Patients diagnosed with BE are 11 times more likely to develop EAC, representing a yearly incidence from $0.12 \%$ to $0.36 \%$ [7]. While GERD and BE are well established risk factors in the development of EAC, malignancy can arise without either being present. Up to $40 \%$ of patients diagnosed with EAC do not have reflux symptoms and a systematic review found that only $24 \%$ to $64 \%$ of resected EAC specimens had histological evidence of BE at the time of surgery [8,9]. Once detected, BE requires periodic surveillance for the development of EAC [4]. Given the proportion of EAC patients presenting without evidence of BE or GERD, population-wide surveillance for $\mathrm{BE}$ remains to be controversial.

The demarcation between gastric and esophageal cancers is an area of ongoing discussion. The 8th edition of the American Joint Committee on Cancer (AJCC) staging guidelines utilized anatomical location to distinguish between gastric adenocarcinoma (GAC) and EAC. Adenocarcinomas with epicenters less than $2 \mathrm{~cm}$ into the gastric cardia are staged as EAC, while tumors greater than $2 \mathrm{~cm}$ into the gastric cardia are staged as GAC [10]. The anatomical approach to staging remains controversial as it does not consider the molecular differences in tumor types. To better classify gastric and esophageal adenocarcinomas, the Cancer Genome Atlas (TCGA) recently performed molecular profiling of both tumor types [11,12]. Researchers subdivided GAC into the following four distinct molecular subtypes: Epstein-Barr virus (EBV)-positive, microsatellite instability (MSI), genomically stable (GS), and chromosomal instability (CIN) [11]. Investigators noted significant molecular similarity between EAC and the CIN subtype of GAC, challenging the notion that these diseases are distinct entities [12]. These studies represent a broader effort to categorize EAC into distinct subpopulations that may be clinically useful for developing and targeting molecular therapies. Thus, in our review, we aim to provide the most current information regarding clinical trials involving targeted molecular therapies, as well as to suggest directions for future investigations.

\section{Current Therapies}

\subsection{Surgery}

Surgical resection remains to be a critical component of the overall treatment regimen of EAC. The choice of surgical approach depends largely on tumor characteristics and location. Patients with localized disease may be candidates for endoscopic interventions. Current guidelines from the National Comprehensive Cancer Network (NCCN) recommend endoscopic mucosal resection (EMR) for patients with Barrett's esophagus, Tis (high-grade dysplasia, carcinoma in situ), T1a, and select T1b lesions without lymphovascular invasion [13].

Patients with resectable lesions who do not meet criteria for endoscopic intervention will generally undergo esophagectomy. For patients with stage I or II disease, surgery has been demonstrated to have similar overall survival and R0 (microscopically margin-negative) resection rates as compared with neoadjuvant chemoradiotherapy followed by surgery [14]. The stomach is the preferred alimentary 
conduit due to its robust and redundant blood supply. In cases where the stomach cannot be safely utilized, a colonic interposition can be performed with good results [15]. The two primary approaches to esophagectomy are the transhiatal or the transthoracic approach. Multiple meta-analysis comparing surgical techniques have not shown a significant difference in the five-year survival between the two approaches, although the transhiatal approach has fewer overall complications with decreased length of hospital stay $[16,17]$.

The minimally invasive esophagectomy (MIE) has become an increasingly popular approach. Comparative results from multi-institutional randomized clinical trials are still needed, however meta-analysis of published data have been able to demonstrate oncologic equivalency between open and minimally invasive approaches [18]. MIE may offer some advantages including reduced in-hospital mortality, shorter hospital stays, enhanced postoperative recovery, and fewer pulmonary and cardiovascular complications [19]. There are multiple ongoing randomized clinical trials comparing MIE to open esophagectomy (ROMIO, ISRCTN 59036820) [20].

\subsection{Chemotherapy}

Numerous phase III randomized clinical trials have evaluated the utility of perioperative chemotherapy and surgery as compared with surgery alone. The MAGIC trial was a landmark study that randomized patients with resectable adenocarcinoma of the stomach, GE junction, and lower esophagus to perioperative epirubicin, cisplatin, 5-fluorouracil (5-FU) and surgery, or surgery alone. There was an improved five-year survival $(36 \%$ vs. $23 \%, p<0.001)$ in perioperative chemotherapy group as compared with surgery alone [21]. The ACCORD-07 and OE02 studies similarly randomized patients to perioperative chemotherapy (cisplatin and 5-FU) and surgery or surgery alone. Both studies demonstrated a significant survival advantage in the perioperative chemotherapy group (ACCORD-07: HR 0.69, $p=0.02$ ) (OE02: HR0.79, $p=0.004$ ) [22,23]. A six-year follow up of the OE02 patients demonstrated a preserved survival advantage in the perioperative chemotherapy group (HR 0.84) with an absolute five-year survival of $23 \%$ vs. $17.1 \%$ [24]. The OE05 trial sought to determine whether increasing the duration and intensity of the neoadjuvant chemotherapy regimen would further improve survival. Patients were randomized to receive two cycles of cisplatin and 5-FU or four cycles of epirubicin, cisplatin, and capecitabine. The intensified neoadjuvant schedule showed no improvement in survival (23.4 vs. 26.1 months). There was no difference in chemotherapy toxicity or surgical complications [25]. The current treatment recommendations for perioperative chemotherapy came from the FLOT-4 study. This phase II/III trial randomized patients with resectable gastroesophageal adenocarcinoma to perioperative epirubicin, cisplatin, and 5-FU/capecitabine, or perioperative 5-FU, leucovorin, oxaliplatin, and docetaxel (FLOT). Results demonstrated significantly improved survival in the FLOT group (HR 0.77, $p=0.012$ ) and similar rates of adverse events, most frequently anemia, neutropenia, nausea, and peripheral neuropathy [26].

\subsection{Chemoradiotherapy}

The use of perioperative chemotherapy has become widely utilized in the treatment of EAC, and many U.S. institutions are now adopting neoadjuvant chemoradiotherapy as the treatment regimen of choice. The CROSS trial was a landmark study that first demonstrated the potential benefit of concomitant chemotherapy and radiotherapy in resectable disease. Patients with resectable lesions of the esophagus or GE junction were randomized to receive neoadjuvant chemoradiation with carboplatin, paclitaxel, and radiation followed by surgery or surgery alone. The chemoradiation group was found to have significantly increased $\mathrm{R} 0$ resection rates ( $92 \%$ vs. $69 \%, p<0.001)$ and improved median overall survival (49.4 vs. 24.0 months, $p<0.003$ ) [27]. Post hoc analysis confirmed this survival advantage in both histological subtypes (EAC and ESCC) independently [28]. While the CROSS study demonstrated a clear survival advantage with neoadjuvant chemoradiation in resectable EAC, the addition of radiotherapy had certain disadvantages. Neoadjuvant radiotherapy has been demonstrated to increase intraoperative risks from bleeding, edema, fibrosis, and inflammation, to increase the incidence of 
postpreparative pulmonary complications including ARDS, and to prolong induction treatment time prior to surgical resection [29-32]. Despite these drawbacks, multiple meta-analyses have demonstrated consistent significant benefits to locoregional control in patients receiving neoadjuvant chemoradiation as compared with chemotherapy alone [33-37].

Chemoradiation can also be used as a definitive therapy for patients with unresectable disease or for those who are unable to tolerate surgery. The landmark RTOG 8501 trial evaluated the potential benefits of definitive chemoradiotherapy in patients with locally advanced, unresectable esophageal cancers. Participants were randomized to receive either radiation or combined radiation plus cisplatin and 5-FU. The study demonstrated a significant five-year survival advantage in the chemoradiation group ( $26 \%$ vs. $0 \%, p<0.001)[38]$.

\section{Targeted Therapies}

Targeted therapies differ from traditional chemotherapy regimens in that they are designed to bind and inhibit specific molecules overexpressed in an individual patient's tumor. The rationale of targeted molecular therapies is rooted in the concept of "oncogene addiction". This term was coined as a means of describing the degree by which tumor cells are dependent on individual oncogenes to sustain their malignant phenotype [39]. Despite the various alterations present in cancer cells, inactivation of even a single oncogene can inhibit cellular growth and proliferation. The theory is that activated oncogenes result in a state of hyperproliferative signaling that, when suddenly inactivated, shift the cellular balance towards proliferative arrest and apoptosis [40]. Perhaps the most famous example of oncogene addiction being exploited for targeted therapeutics is in chronic myeloid leukemia (CML). This disease is driven by a chromosomal translocation resulting in the $B C R-A B L$ mutant oncogene. Direct inhibition of this oncogene via the small molecule kinase inhibitor imatinib (Gleevec) resulted in a major clinical response in $87 \%$ of treated CML patients as compared with just $35 \%$ clinical response in a comparison group receiving interferon alfa plus cytarabine $(p<0.001)$ [41]. The concept of oncogene addiction is not universal and targeting certain oncogenes may not result in a complete response. It is important to understand the circumstances by which oncogene inactivation induces apoptosis, differentiation, and senescence in the context of heterogenous and complex activation of multiple signaling networks within a tumor. This knowledge will help to guide development of novel and effective strategies in the treatment of cancer [42]. In the following sections, we will briefly review the current state of targeted molecular therapies in the treatment of EAC (Figure 1).

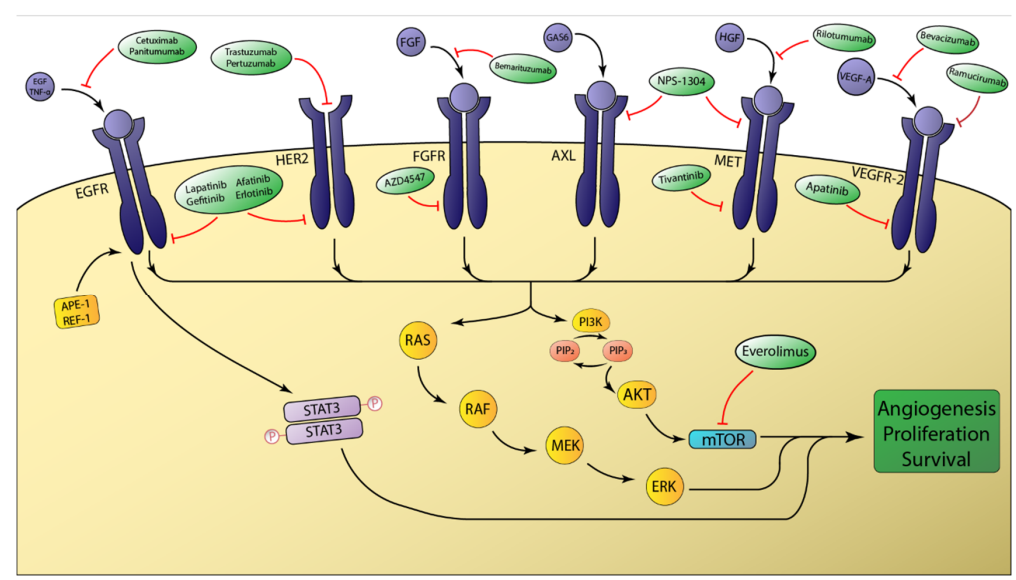

Figure 1. Schematic overview of select receptor tyrosine kinases involved in esophageal adenocarcinoma tumorigenesis. The intracellular signaling of the depicted receptor tyrosine kinases (RTKs) is primarily mediated by the RAS/RAF and PI3K/AKT pathways. Aberrant activation of these pathways ultimately favors tumor growth and survival. mTOR is a major downstream effector that is modulated by AKT signaling. Molecular therapies targeting RTKs either disrupt ligand binding or function to prevent intracellular activation of the tyrosine kinase domain. 


\subsection{The ErbB Receptor Family}

The erbB family comprises a group of tyrosine kinase receptors that integrate external stimuli with specific internal signals that allow cells to appropriately respond to the environment. Overexpression and aberrant function of receptors belonging to this family have been frequently implicated in many human cancers. This family contains the following four distinct receptors: erbB1 (EGFR/HER1), erbB2 (HER2/Neu), erbB3 (HER3), erbB4 (HER4). These receptors share the same molecular structure with an extracellular binding domain, a short transmembrane domain, and an intracellular domain. Except for HER3, the intracellular domain has tyrosine kinase activity [43]. The formation of erbB homo and heterodimers upon ligand binding activates the intrinsic receptor tyrosine kinase (RTK) activity via intramolecular phosphorylation and generates downstream signaling effects via activation of the RAS/RAF and PI3K/AKT pathways (Figure 1) [44].

\subsection{Epidermal Growth Factor Receptor}

The epidermal growth factor receptor (EGFR) plays an integral role in normal cell growth and differentiation. Its primary ligands are EGF and TGF- $\alpha$ [44]. Aberrant activation of EGFR via amplification, overexpression, or mutation has been demonstrated to induce tumor cell proliferation, migration, and metastasis. EGFR has been found to be preferentially amplified in patients with poorly differentiated EAC [45]. The overall prevalence of EGFR amplification in EAC has been reported to be between 4 and 6\% [46]. EGFR has been shown to be a key mediator in the neoplastic progression to EAC. Apurinic/apyrimidinic endonuclease 1 (APE1) is constitutively overexpressed in EAC and can be induced in non-neoplastic esophageal tissue after exposure to acidic bile salts (ABS). APE1 induction activates EGFR which subsequently phosphorylates and activates STAT3. The ultimate consequence of APE1-EGFR-STAT3 axis activation in EAC is constitutive STAT3 signaling which results in a survival advantage and promoted cell proliferation (Figure 1) [47]. Caudal homeobox 2 (CDX2) induction has also been implicated in the metaplastic transition to Barrett's esophagus [48]. The mechanism by which ABS induces CDX2 expression is through ligand-dependent transactivation of EGFR [49]. EGFR plays an integral role in EAC tumorigenesis and, as such, has been the subject of investigation for targeted molecular therapies.

Cetuximab and panitumumab are monoclonal antibodies directed against EGFR and both are currently FDA approved for the treatment of KRAS-wild type metastatic colorectal cancer [50]. A recent phase III clinical trial evaluated the utility of cetuximab in patients with locally advanced, unresectable, or metastatic gastroesophageal adenocarcinoma. Patients were randomized to receive standard chemotherapy with or without cetuximab. Surprisingly, the addition of cetuximab resulted in worse progression-free survival (4.4 vs. 5.6 months) [51]. A separate phase III trial evaluating panitumumab also demonstrated worse overall survival in a similar patient population [52].

Small molecule tyrosine kinase inhibitors are a separate class of targeted therapeutics that competitively bind the ATP binding site of the intracellular tyrosine kinase domain of EGFR and other tyrosine kinase receptors. This prevents intracellular signal transduction even in the presence of bound ligand. Gefitinib is a small molecule inhibitor of HER2 and EGFR. Preclinical studies have demonstrated good antitumor activity of gefitinib in EAC cell lines, especially those with EGFR polysomy [53]. The COG trial was a randomized phase III trial studying gefitinib in patients with chemoresistant EAC and ESCC. There was no survival difference in patients receiving gefitinib or placebo (3.73 vs. 3.67 months) [54]. Subgroup analysis, however, demonstrated that, in the $20.2 \%$ of enrolled patients who had EGFR copy number gain (CNG) demonstrated by fluorescent in situ hybridization (FISH), there was significantly improved overall survival with gefitinib (HR 0.59, $p=0.05$ ). Those patients with EGFR amplification (7.2\%) benefited the most from gefitinib therapy (HR 0.21, $p=0.006$ ) [55]. More recent investigations have mirrored the COG subgroup analysis and evaluated whether EGFR CNG could be a biomarker predictive of response to anti-EGFR therapy [56]. Post hoc analysis of multiple larger clinical trials has uncovered an association between the EGFR amplified subpopulation and overall survival [55,57]. In a large single-intuition cohort of patients with metastatic 
gastroesophageal adenocarcinoma with EGFR amplification, anti-EGFR therapy was found to provide an excellent clinical response in a majority of patients [58]. Larger studies validating the EGFR CNG biomarker may uncover some benefit in this class of targeted therapeutics.

\subsection{Human Epidermal Growth Factor Receptor 2}

The human epidermal growth factor receptor 2 (HER2) is the second member of the erbB family of receptors and shows significant homology to EGFR. Interestingly, HER2 is the only member of this receptor family that has no identified natural ligand and often heterodimerizes with other erbB receptors [44]. Heterodimers that form with HER2 generate intracellular signals that are significantly more robust than other erbB receptors [59]. HER2 signaling is involved in various cellular functions including cell growth, survival, and differentiation. The primary HER2-mediated signal transduction pathways involve mitogen-activated protein kinase (MAPK) and phosphatidylinositol 3-kinase (PI3K) [60]. HER2 amplification has been demonstrated to be a poor prognostic indicator and oncogenic amplifications of HER2 have been reported in 20-30\% of EAC cases as compared with just $3 \%$ in ESCC [12,61].

Trastuzumab is a humanized monoclonal antibody targeting the extracellular domain of HER2 that has become the standard of care for patients with HER2-positive breast cancer [62]. The trastuzumab for gastric cancer (TOGA) trial evaluated patients with advanced gastroesophageal adenocarcinoma with confirmed overexpression of HER2 (via FISH or IHC). Participants were randomized to receive standard chemotherapy with or without trastuzumab. The results demonstrated significantly improved overall survival (13.8 vs. 11.1 months, $p=0.0046)$ in the trastuzumab group [63]. Unfortunately, this survival advantage was not observed in a recently reported phase III trial evaluating the addition of trastuzumab to neoadjuvant chemoradiation in the setting of resectable, HER2-positive EAC [64].

Pertuzumab is another humanized monoclonal antibody targeting HER2 that was specifically developed to prevent HER2 dimerization. Pertuzumab binds to a different epitope on the extracellular domain of HER2 and functions to sterically block HER2 dimerization [65]. Preclinical studies have demonstrated synergistic antitumor activity when combined with trastuzumab $[66,67]$. In HER2-positive metastatic breast cancer, phase III clinical trials have demonstrated significantly longer progression-free survival in patients receiving the combination of pertuzumab and trastuzumab [68]. A similar phase III trial was conducted to evaluate the use of dual HER2 therapy in patients with HER2-positive, metastatic gastroesophageal adenocarcinoma. Patients were treated with trastuzumab and chemotherapy with either pertuzumab or placebo. The results demonstrated a modest but not statically significant improvement in overall survival with the addition of pertuzumab (17.5 vs. 14.2 months, $p=0.057$ ) [69]. A recently published phase II study evaluated the feasibility of adding pertuzumab and trastuzumab to standard neoadjuvant chemoradiotherapy in patients with resectable, HER2-positive EAC. Investigators demonstrated the feasibility of dual HER2 blockade through exploratory propensity score-matched comparisons to a cohort receiving standard neoadjuvant chemoradiotherapy and demonstrated significantly longer overall survival (HR $0.58, p<0.05)$ with dual anti-HER2 therapy [70]. Larger phase III trials will be needed to determine if targeted dual HER2 therapy has a role in the neoadjuvant setting for the treatment patients with resectable disease.

Unfortunately, trastuzumab's clinical effect in gastroesophageal adenocarcinoma has been modest as primary resistance is common and acquired resistance develops quickly. A recent phase II study characterized tumors resistant to targeted therapy. Investigators uncovered an association between co-amplification of EGFR and HER2 and better clinical response to targeted HER2 therapy [71]. Further investigation is warranted to determine if differential expression of HER2 and EGFR can predict clinical response to targeted therapies in HER2-amplified EAC.

\subsection{Vascular Endothelial Growth Factor}

The interactions between vascular endothelial growth factors (VEGF) and VEGF receptors (VEGFR) are the principle means for regulation of angiogenesis. These interactions play a key role 
in tumor growth and metastasis [72]. VEGF-A is the primary ligand involved in tumor angiogenesis and binds with high affinity to VEGFR-1 and VEGFR-2, although most proangiogenic effects are mediated by VEGFR-2 [73]. VEGF is commonly elevated in solid tumors due to intra-tumoral hypoxia. Hypoxia induces VEGF via hypoxia inducible factors (HIF) $1 \alpha$ and $2 \alpha$ [74]. The angiogenic properties of EAC are often acquired early in the tumorigenesis of EAC. While VEGF expression has been associated with tumor progression and metastasis in ESCC, there has been little evidence of similar prognostic indication in EAC [75]. A study of the Barrett's adenocarcinoma cell line OE33 demonstrated increased VEGF expression following exposure to ABS [76]. This upregulation of VEGF suggests that acid reflux has the potential to contribute to tumorigenesis via angiogenesis.

Bevacizumab is a monoclonal antibody directed against VEGF-A. It has been FDA approved for the treatment of various solid tumors including metastatic colorectal cancer, glioblastoma, non-small cell lung cancer, and cervical cancer [77]. In phase III trials, the addition of bevacizumab to capecitabine and cisplatin in patients with advanced gastroesophageal adenocarcinoma demonstrated no significant improvement in overall survival ( 12.1 vs. 10.1 months, $p=0.1002)$. While the primary endpoint was not met, the study did reveal significantly improved progression-free survival (6.7 vs. 5.3 months, $p=0.0037$ ) and overall clinical response rate $(46.0 \%$ vs. $37.4 \%, p=0.0315)$ for patients receiving bevacizumab [78]. A phase II/III trial evaluating the addition of bevacizumab to a perioperative chemotherapy regimen demonstrated no significant increase in three-year overall survival $(50.3 \%$ vs. $48.1 \%, p=0.36)$, higher incidence of wound healing complications ( $12 \%$ vs. $7 \%)$, and higher anastomotic leak rates ( $24 \%$ vs. $10 \%)$ with the addition of bevacizumab [79].

Ramucirumab is a newer IgG1 monoclonal antibody targeting VEGFR-2 that showed robust activity in the preclinical setting [80]. A phase III trial evaluating patients with advanced, chemoresistant gastroesophageal adenocarcinoma randomized patients to receive ramucirumab or placebo. There was a significant overall survival advantage (5.2 vs. 3.8 months, $p=0.047$ ) in the ramucirumab group [81]. A separate study evaluating the same patient population randomized participants to receive second-line therapy with paclitaxel and ramucirumab or paclitaxel alone. Overall survival was again found to be significantly longer in the ramucirumab group (9.6 vs. 7.4 months, $p=0.017$ ) [82]. These trials resulted in the FDA approving ramucirumab in combination with paclitaxel as a second-line therapy for the treatment of advanced gastroesophageal adenocarcinoma [83]. More recent studies evaluating ramucirumab as a first-line agent have been less successful. Patients with HER2-negative gastroesophageal adenocarcinoma were randomized to receive cisplatin plus capecitabine with either ramucirumab or placebo. The results demonstrated no significant improvement in progression-free survival or overall survival [84].

Apatinib is a small molecule inhibitor that is highly selective for VEGF-2. A recent phase III trial evaluated its utility in treating patients with advanced, chemoresistant gastroesophageal adenocarcinoma. Results demonstrated significantly prolonged median overall survival (6.5 vs. 4.7 months, $p=0.0149$ ) and progression-free survival ( 2.6 vs. 1.8 months, $p<0.001$ ) in patients receiving apatinib compared to placebo [85].

VEGF-targeted therapy appears to have a role in the overall treatment paradigm of EAC. There are multiple ongoing clinical trials attempting to identify the setting in which VEGF therapy would be most beneficial. The postoperative complications associated with VEGF-targeted therapy, have limited its utility to patients with advanced, unresectable disease, although smaller studies have suggested these adverse postoperative effects may be less severe with apatinib [86]. Further investigations are warranted to discover if apatinib has a place in the treatment of resectable disease.

\subsection{Mesenchymal-Epithelial Transition Factor}

The mesenchymal-epithelial transition (MET) proto-oncogene is often implicated in a multitude of cancers and plays a role in tumorigenesis and metastasis. MET encodes the receptor tyrosine kinase MET (or cellular MET, c-MET). Its ligand, hepatocyte growth factor (HGF), is primarily secreted by cells of mesenchymal origin [87]. MET activation triggers diverse signaling pathways that are primarily 
mediated by the RAS/RAF and PI3K/AKT pathways [88]. Aberrant MET activation plays a critical role in tumor cell proliferation, invasion, and angiogenesis [89]. Genomic amplification of MET has been demonstrated to be a poor prognostic indicator in EAC [90,91].

Our understanding of the role MET plays in tumor biology has made it an attractive target in the development of novel therapeutics. Unfortunately, most phase III clinical trials have been unable to demonstrate a role for targeted MET inhibition in the treatment of EAC. Rilotumumab is a monoclonal antibody targeting HGF. A phase III trial evaluating rilotumumab in patients with MET-positive gastroesophageal adenocarcinoma was ended early after results demonstrated worse median overall survival ( $8.8 \mathrm{vs}$. 10.7 months) with the addition of rilotumumab to standard chemotherapy [92]. Onartuzumab is another monoclonal antibody targeting the extracellular domain of MET to prevent HGF binding. A phase III trial evaluating the addition of onartuzumab to standard first line mFOLFOX6 in patients with HER2-negative, MET-positive gastroesophageal adenocarcinoma demonstrated no improvement in overall survival (11.0 vs. 11.3 months) or progression-free survival (6.7 vs. 6.8 months) [93]. While trials involving anti-MET antibodies have been unsuccessful, MET small molecule inhibitors have shown promising results. Tivantinib is one such small molecule inhibitor that preferentially interacts with tumor cells overexpressing MET [94]. A phase II trial evaluating the addition of tivantinib to standard FOLFOX for metastatic gastroesophageal adenocarcinoma showed improved progression-free survival as compared with historical controls [95]. While these findings are encouraging, further phase III are warranted to validate the results. Targeted MET therapy may also be a means of overcoming resistance to other targeted therapeutics. For example, a study of HER2 resistant tumors uncovered an association between resistance and MET amplification. Patient-derived xenograft models, established from these co-amplified tumors, demonstrated complete tumor regression with dual HER/MET inhibition [71]. Further investigation is needed to determine if the observed preclinical effect of combined HER2/MET inhibition is a viable strategy to overcome HER2 resistance.

\subsection{Fibroblast Growth Factor Receptor}

The fibroblast growth factor receptor (FGFR) family is another RTK known to be involved in tumor growth, survival, resistance to chemotherapeutic regimens, and angiogenesis [96]. To date, four distinct FGFR receptors have been identified (FGFR1-4). Similar to many other RTKs, interaction of FGFR with its ligand triggers an intracellular signaling cascade primarily through PI3K/AKT and RAS/RAF pathways [97]. Genomic amplification of FGFR1 and FGFR2 has been reported in $3-4 \%$ of EAC samples and appeared to confer a poor prognostic in gastric adenocarcinoma [12,98].

Bemarituzumab is a humanized monoclonal antibody targeting FGFR2b. Mechanistically, bemarituzumab inhibits ligand binding and induces internalization and degradation of FGFR2b [99]. Phase I and II trials, evaluating the utility of bemarituzumab in treating FGFR2b-overexpressed (via IHC or circulating tumor DNA) advanced gastric cancers, demonstrated adequate safety profiles and significant antitumor activity [100]. Planned phase III trials are underway to evaluate if the addition of bemarituzumab to standard FOLFOX6 chemotherapy is beneficial in this subset of FGFR2b amplified tumors [99].

AZD4547 is a highly selective small molecule tyrosine kinase inhibitor of FGFR1-3. Preclinical studies have shown good results in FGFR2 amplified cell lines and mouse models [101]. A recent phase II trial selected patients with advanced gastric adenocarcinoma and FGFR2 polysomy or gene amplification (via FISH) to receive AZD4547 or paclitaxel. The results demonstrated no significant improvement in progression-free survival. Exploratory biomarker analysis of FGFR2 amplification/polysomy demonstrated poor concordance with measured FGFR2 mRNA expression and significant intra-tumoral heterogeneity [102]. The inability to select for clonally amplified tumors may explain why the preclinical efficacy of AZD4547 was unable to be translated in clinical trials. Perhaps utilization of circulating tumor DNA, as a means of selecting the appropriate study population, will lead to better results in future investigations. 
FGFR2 plays a critical role in angiogenesis by promoting proliferation and migration of vascular endothelial cells, especially in combination with VEGF [103]. A phase II study evaluating biomarkers for resistance to anti-VEGF therapy in metastatic colorectal cancer found significantly increased FGFR expression [104]. Multiple studies have demonstrated enhanced anti-angiogenic effects with dual FGFR/VEGF therapy in solid tumors $[105,106]$. The combination of dual inhibition of VEGF and FGFR has yet to be evaluated in EAC and is a promising area of future studies.

\subsection{Mammalian Target of Rapamycin}

The mammalian target of rapamycin (mTOR) is a master regulator of cellular growth, proliferation, and survival [107]. Many RTKs achieve downstream effects through signaling primarily mediated by the RAS/RAF and PI3K/AKT pathways. mTOR is downstream from these signaling pathways and is one of the major effectors regulated by PI3K/AKT signaling [108]. Aberrant regulation of mTOR has been proposed as a potential mechanism for the ineffectiveness of previously mentioned RTK-targeted therapies [109].

Everolimus is an oral mTOR inhibitor that has been approved for the treatment of advanced renal cell carcinoma and advanced breast cancer $[110,111]$. Preclinical studies have demonstrated significant tumor activity of everolimus in gastric cancer cell lines [112]. Phase III trials of patients with advanced gastroesophageal adenocarcinoma demonstrated modest, but not significant improvement in overall survival with the addition of everolimus to standard chemotherapy (5.4 vs. 4.3 months, $p=0.124$ ) [113]. A more recent phase II trial identified pS6 as a potential biomarker in patients with advanced gastroesophageal adenocarcinoma who responded to everolimus [114]. Further investigations are needed to validate pS6 as a positive predictor marker and to uncover other potential biomarkers to stratify patients who would best respond to targeted mTOR therapy.

\subsection{Heat Shock Protein 90}

Heat shock proteins (HSP) are a family of molecular chaperones that are often a cellular response to stressful conditions. They function to prevent aggregation of misfolded proteins by ubiquitin-targeted degradation and to assist proper protein folding [115]. HSP90 is a member of this molecular chaperone family and is overexpressed in EAC [116]. In cancer cells, HSP90 can act to stabilize mutated or overexpressed oncogenic client proteins [117]. Targeted therapy allows HSP90 to release bound client proteins which can subsequently be degraded [118].

HER2 is an HSP90 client protein that has been the subject of recent investigations. A study of human EAC samples demonstrated a strong positive correlation between HSP90 expression and HER2 status, suggesting coregulation in a subset of EAC patients [119]. In fact, some data suggest that dysregulated HSP90 expression may be responsible in potentiating the oncogenic effects of HER2, representing a potential mechanism of resistance to HER2-targeted therapies [120]. Studies investigating the effects of combined HER-2 and HSP90 inhibition in trastuzumab or lapatinib-resistant gastric cancer models have shown significant synergistic antitumor activity [121,122]. While clinical trials studying combined therapy in EAC are lacking, a published phase II trial found that a majority (69\%) of patients with metastatic breast cancer, treated with the combination of the HSP90 inhibitor AUY992 and trastuzumab, achieved clinical response or stable disease [123]. In EAC models, AUY992 has demonstrated robust antitumor activity when combined with 5-FU and cisplatin [124]. An ongoing phase II clinical trial is evaluating the effects of AUY922 with docetaxel and irinotecan in patients with advanced gastroesophageal adenocarcinoma (NCT 01084330). Ganetespib is a recently developed small molecule inhibitor of HSP90 that is currently being investigated in a phase I clinical trial (NCT 02389751) in combination with carboplatin, paclitaxel, and radiation for patients with stage II-III EAC. Targeted HSP90 therapy may provide a means to overcome resistance to previously mentioned RTK-targeted therapeutics. 


\subsection{Aurora Kinase A}

Aurora kinase A (AURKA) is one of three mammalian serine-threonine protein kinases in the aurora kinase family. AURKA plays a critical role in mitotic spindle formation and centrosome development. The AURKA gene is located on chromosome $20 \mathrm{q} 13$, a locus that is frequently amplified in gastroesophageal adenocarcinoma [125]. Preclinical studies have demonstrated AURKA overexpression to impair DNA damage repair through inhibition of RAD51, BRCA1, and BRCA2 [126-128] (Figure 2). AURKA also significantly inhibits the tumor-suppressive functions of p53 and p73 [129]. The inhibition of p53 occurs by the following two distinct mechanisms: MDM2-mediated degradation and direct phosphorylation at Ser315 and Ser215 [130,131]. Furthermore, AURKA overexpression leads to phosphorylation of GSK-3 $\beta$, which in turn decreases phosphorylation of beta-catenin and ultimately results in increased oncogenic signaling of the beta-catenin/TCF transcription complex [132]. Moreover, AURKA can induce inflammation in gastric cancer cells through induction of NF- $\mathrm{B}$ [133]. Because of its intimate role in tumorigenesis, AURKA-targeted therapy has been the focus of recent drug development. AURKA therapy in EAC is particularly interesting, due to the abundance of p53 mutations or deficiencies in human tumors [134].

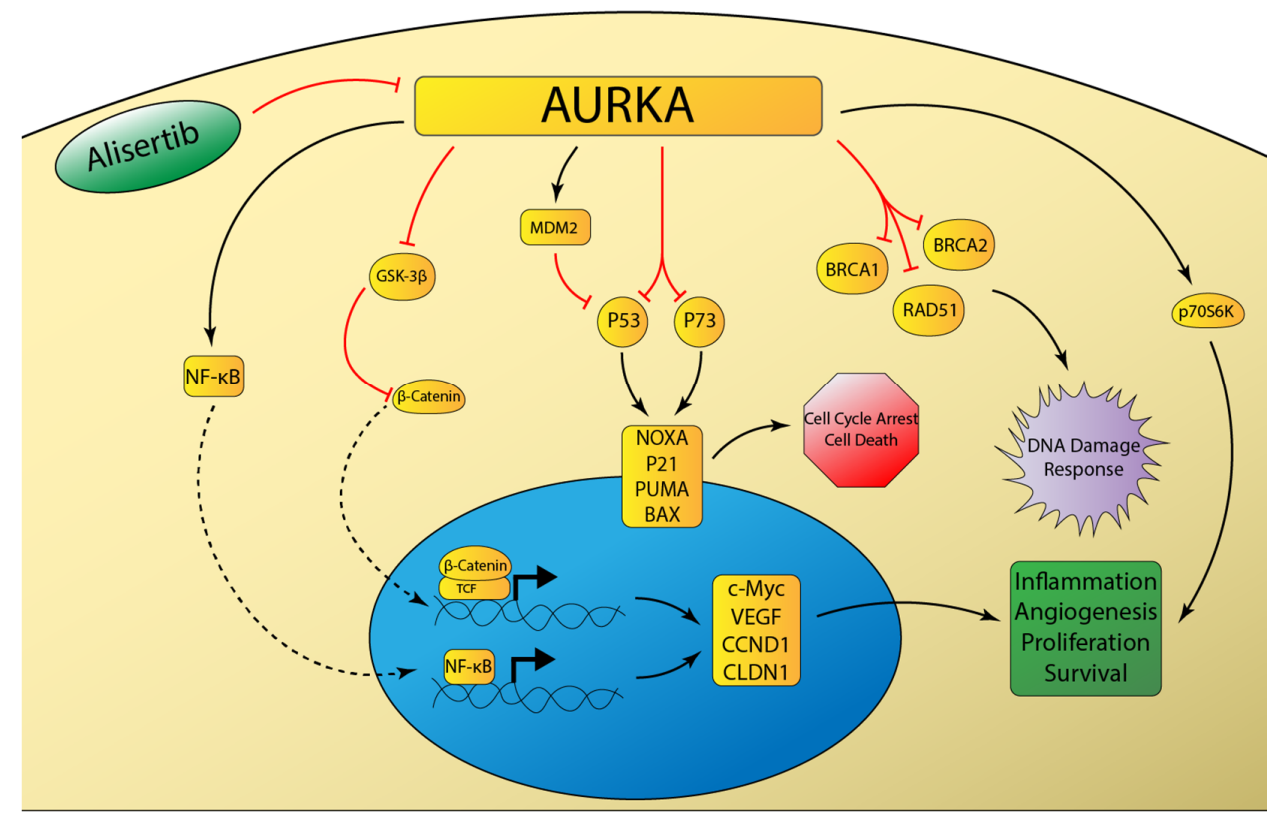

Figure 2. Schematic representation of aurora kinase A (AURKA) signaling networks involved in cancer. AURKA overexpression inhibits the DNA damage response and attenuates DNA-damage induced cell cycle arrest and apoptosis through inhibition of p53 family member proteins [129]. AURKA induces inflammatory signaling mediated by NF- $\mathrm{B}$ [133], as well as pro-survival signaling mediated by beta-catenin [132] and p70S6K [135].

The identification of AURKA as a druggable target has spurred the development of many investigational agents targeting AURKA. Alisertib (MLN8237) is a selective inhibitor of AURKA and has been shown in preclinical studies to induce mitotic spindle abnormalities, mitotic accumulation, and apoptosis [136]. Studies of EAC models have demonstrated robust antitumor activity, especially when combined with cisplatin and docetaxel [137,138]. A recent phase I/II trial evaluated the antitumor activity of alisertib in a variety of advanced solid tumors including breast cancer, lung cancer, and gastroesophageal adenocarcinoma. The results demonstrated a manageable safety profile and promising antitumor activity, although this effect was less pronounced in the gastroesophageal cohort [139]. The frequency of AURKA overexpression in EAC makes it an attractive target for further drug development and clinical trials. While preclinical models have shown promising results, further trials are needed to determine if AURKA inhibition provides real clinical benefit. 


\subsection{0. $A X L$}

The AXL gene encodes a receptor tyrosine kinase in the TAM family [140]. Upon interaction with its ligand, GAS6 (growth arrest-specific gene 6), AXL results in activation of the PI3K/AKT and RAS/RAF pathways. Aberrant activation of these pathways drives angiogenesis, proliferation, survival, invasiveness, and the epithelial to mesenchymal (EMT) transition [141]. AXL overexpression is a poor prognostic indicator in EAC [142]. Preclinical studies have demonstrated that aberrant AXL expression was intimately involved in the resistance of EAC to standard chemotherapeutic regimens. AXL was found to mediate resistance to cisplatin through disruption of c-ABL nuclear accumulation in response to DNA damage [143]. Additionally, AXL can promote resistance to epirubicin via transcriptional upregulation of c-MYC. In fact, AXL knockdown or pharmacologic AXL inhibition sensitizes resistant cells to epirubicin [144]. Preclinical investigations have also demonstrated that AXL activation mediated resistance to EGFR-targeted therapeutics in lung cancer [145]. Subsequent studies have demonstrated that the AXL inhibitor NPS-1034 was effective in rendering these cells sensitive to EGFR-therapy [146]. While further investigation is warranted, AXL blockade may be exploited to sensitize EAC cells to standard chemotherapy regimens or to targeted EGFR therapeutics.

\section{Immune Checkpoint Inhibitors}

The T-cell immune response is a tightly regulated process that functions by costimulatory and coinhibitory mechanisms to identify foreign antigens and protect the host from autoimmunity. Cancer cells will often express various tumor-specific antigens that allow T-cells to recognize the tumor as foreign and induce cell death via apoptosis. Cancer cells, however, can escape immune recognition by expressing coinhibitory signals known as immune checkpoints [147] (Figure 3). Programmed death 1 (PD-1) is a receptor expressed on T-cells that functions primarily to maintain peripheral tolerance by inhibiting T-cell activation. Its ligand, PD-L1, is often overexpressed in cancer cells which allows the tumor to escape immune surveillance [148]. Cytotoxic T lymphocyte-associated antigen 4 (CTLA-4) is another coinhibitory immune checkpoint that suppresses T-cell activation. A critical step in T-cell activation involves the binding of the B7 ligand of tumor cells to the CD28 receptor of T-cells. CLTA-4 functions to inhibit T-cell activity by competing with CD28 for B7, for which CTLA-4 has a significantly higher affinity [149].

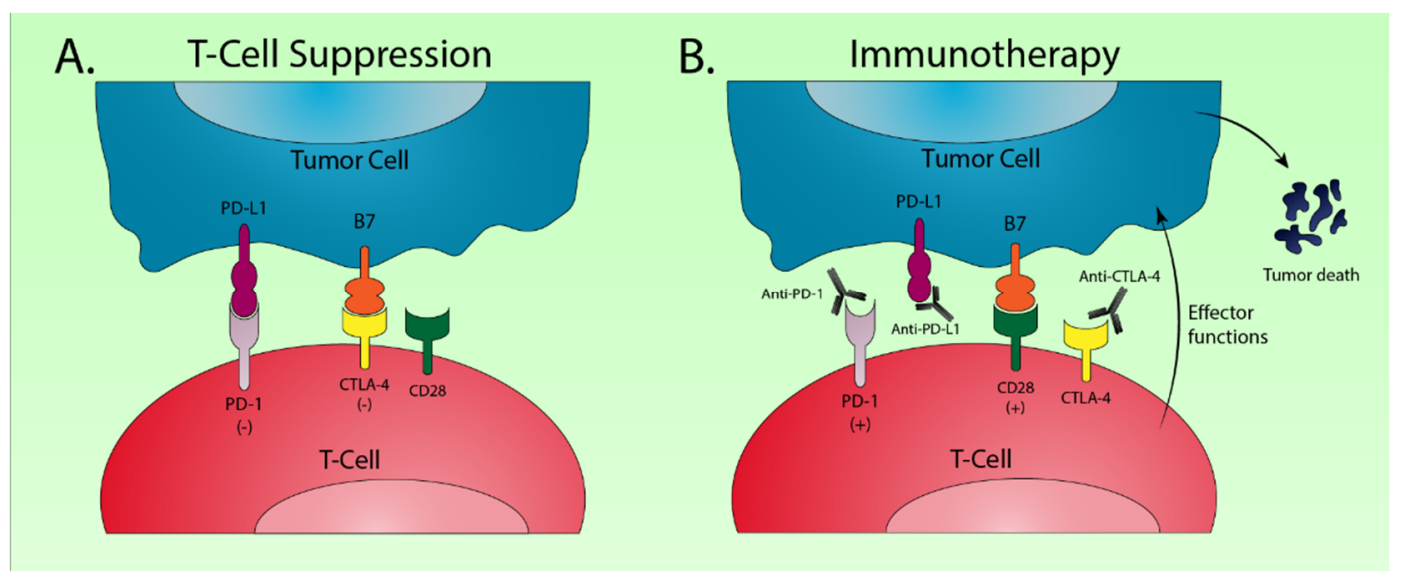

Figure 3. Schematic drawing of the major molecular mechanisms involved in checkpoint blockade for cancer immunotherapy. (A) Interaction of the programmed death 1 (PD-1) receptor on T-cells with the programmed death ligand 1 (PD-L1) on tumor cells results in T-cell suppression [148]. A similar suppressive interaction occurs between B7 on tumor cells and cytotoxic T lymphocyte-associated antigen 4 (CTLA-4) on T-cells [149]; (B) Monoclonal antibodies targeting PD-1 and PD-L1 disrupt T-cell checkpoint suppression and facilitate antitumor T-cell effector functions. Anti-CTLA-4 therapy allows binding of B7 with CD28 on T-cells which stimulates further T-cell activation. 
Cancer immunotherapy utilizes monoclonal antibodies directed against immune checkpoint proteins such as PD-1, PD-L1, and CTLA-4 to enable T-cell recognition of tumor cells, and delivers the antitumor immune response. Molecular characterization of gastroesophageal adenocarcinoma has uncovered significant immune dysregulation in EBV and MSI subtypes [11]. In fact, high MSI was predictive of solid tumor response to PD-1 inhibition [150]. Pembrolizumab is a monoclonal antibody that binds to PD-1. It was granted FDA approval as a third line therapy in advanced gastroesophageal adenocarcinoma expressing PD-L1 with high MSI or deficient mismatch repair (MMR) [151]. More recently, pembrolizumab has been investigated as a potential first-line option. KEYNOTE-062 (NCT 02494583) is an ongoing phase III study which randomized patients with advanced gastroesophageal adenocarcinoma to receive pembrolizumab, pembrolizumab plus chemotherapy, or chemotherapy alone. Preliminary results demonstrated non-inferiority of single agent pembrolizumab as compared with standard chemotherapy. Pembrolizumab monotherapy also improved median overall survival (17.4 vs. 10.8 months) in patients with high PD-L1 expression [152]. While researchers could not claim statistical significance due to study design, it appeared that pembrolizumab was superior to standard chemotherapy in this subset of patients. Nivolumab is another monoclonal antibody targeting PD-1 that has been investigated in phase III trials, both as a salvage therapy and a first line agent. Patients with advanced gastroesophageal adenocarcinoma who had failed previous chemotherapy regimens demonstrated significantly improved overall survival (5.3 vs. 4.1 months, $p<0.0001$ ) with nivolumab as compared with the placebo [153]. Recently reported results from the CheckMate 649 trial show significantly improved overall survival (14.4 vs. 11.1 months, $p<0.0001)$ and progression-free survival (7.7 vs. 6.1 months, $p<0.0001)$ when adding nivolumab to standard first line chemotherapy in patients with advanced gastroesophageal adenocarcinoma and high PD-L1 expression. Interestingly, trial participants were not selected for PD-L1 expression upon enrolment and a significant overall survival advantage (13.8 vs. 11.6 months, $p=0.0002)$ was demonstrated in the entire study population regardless of PD-L1 expression [154].

Dual immune checkpoint blockade is an emerging and exciting area of investigation. Ipilimumab is a monoclonal antibody, which targets CTLA-4, that has been combined with nivolumab to achieve significant survival benefits in metastatic melanoma, small-cell lung cancer, and MMR deficient/high MSI colorectal cancer [155-157]. A Phase II trial demonstrated significant antitumor activity and durable response with combined ipilimumab and nivolumab therapy in patients with advanced gastroesophageal adenocarcinoma [158]. Larger phase III trials are currently underway evaluating this drug combination in both advanced (NCT 03143153) and resectable (NCT 03604991) EAC.

\section{Conclusions}

While significant strides have been made in the treatment of EAC, survival remains poor and therapeutic advancements have not kept pace with other GI malignancies. The ability to readily perform molecular profiling has ushered in a new wave of investigations into targeted molecular therapeutics and immunotherapies. Current first-line treatments of EAC are often met with therapeutic resistance. Molecular profiling of these resistant tumors has helped investigators to identify differentially expressed biomarkers that can be exploited to overcome resistance. Many of these mechanisms have only been described in a preclinical setting and are yet to be applied in clinical trials. The next five years will likely see a dramatic shift in the overall treatment paradigm of EAC, especially when it comes to tumors resistant to first-line agents.

First-line therapies will also likely change as investigations into immunotherapies continue. Recent studies are even challenging the notion that positive biomarkers such as PD-L1 are necessary to observe a clinical benefit with anti-PD-L1 immunotherapies. Further improvements in immunotherapies and the identification of druggable targets will likely result from a more in-depth understanding of molecular signatures and tumorigenesis. Clinicians will likely need to revisit the idea of tailoring first-line treatment regiments based on tumor stage, instead of focusing on the molecular profile. 
Author Contributions: Conceptualization, S.K. and W.E.R.; methodology, S.K. and W.E.-R.; software, S.K.; validation, W.E.-R., A.C.L., and A.S.L.; investigation, S.K.; resources, S.K.; data curation, S.K.; writing-original draft preparation, S.K.; writing-review and editing, W.E.-R., A.C.L., and A.S.L.; visualization, S.K.; supervision, W.E.-R. and A.C.L.; project administration, W.E.-R. All authors have read and agreed to the published version of the manuscript.

Funding: This work was supported by the National Institute of Health Grant T32 CA211034 awarded to N.B. Merchant. The contents of this work are solely the responsibility of the authors and do not necessarily represent the official views of the National Institute of Health.

Conflicts of Interest: The authors declare no conflict of interest.

\section{References}

1. Bray, F.; Ferlay, J.; Soerjomataram, I.; Siegel, R.L.; Torre, L.A.; Jemal, A. Global cancer statistics 2018: GLOBOCAN estimates of incidence and mortality worldwide for 36 cancers in 185 countries. CA Cancer J. Clin. 2018, 68, 394-424. [CrossRef] [PubMed]

2. Siegel, R.L.; Miller, K.D.; Jemal, A. Cancer statistics, 2020. CA Cancer J. Clin. 2020, 70, 7-30. [CrossRef] [PubMed]

3. Howlader, N.; Noone, A.M.; Krapcho, M.; Miller, D.; Brest, A.; Yu, M.; Ruhl, J.; Tatalovich, Z.; Mariotto, A.; Lewis, D.R.; et al. SEER Cancer Statistics Review, 1975-2016; National Cancer Institute: Bethesda, MD, USA, 2020. Available online: www.seer.cancer.gov/archive/csr/1975_2016/ (accessed on 21 May 2020).

4. Coleman, H.G.; Xie, S.H.; Lagergren, J. The Epidemiology of Esophageal Adenocarcinoma. Gastroenterology 2018, 154, 390-405. [CrossRef] [PubMed]

5. Lagergren, J.; Smyth, E.; Cunningham, D.; Lagergren, P. Oesophageal cancer. Lancet 2017, 390, 2383-2396. [CrossRef]

6. Mukaisho, K.I.; Kanai, S.; Kushima, R.; Nakayama, T.; Hattori, T.; Sugihara, H. Barretts's carcinogenesis. Pathol. Int. 2019, 69, 319-330. [CrossRef] [PubMed]

7. Alsop, B.R.; Sharma, P. Esophageal Cancer. Gastroenterol. Clin. N. Am. 2016, 45, 399-412. [CrossRef]

8. Chang, J.T.; Katzka, D.A. Gastroesophageal reflux disease, Barrett esophagus, and esophageal adenocarcinoma. Arch. Intern. Med. 2004, 164, 1482-1488. [CrossRef]

9. Dulai, G.S.; Guha, S.; Kahn, K.L.; Gornbein, J.; Weinstein, W.M. Preoperative prevalence of Barrett's esophagus in esophageal adenocarcinoma: A systematic review. Gastroenterology 2002, 122, 26-33. [CrossRef]

10. Rice, T.W.; Patil, D.T.; Blackstone, E.H. 8th edition AJCC/UICC staging of cancers of the esophagus and esophagogastric junction: Application to clinical practice. Ann. Cardiothorac. Surg. 2017, 6, 119-130. [CrossRef]

11. Cancer Genome Atlas Research Network. Comprehensive molecular characterization of gastric adenocarcinoma. Nature 2014, 513, 202-209. [CrossRef]

12. Cancer Genome Atlas Research Network; Analysis Working Group: Asan University; B. C. Cancer Agency; Brigham Women's Hospital; Broad Institute; Brown University; Case Western Reserve University; Dana-Farber Cancer Institute; Duke University; Greater Portland Cancer Centre; et al. Integrated genomic characterization of oesophageal carcinoma. Nature 2017, 541, 169-175. [CrossRef]

13. National Comprehensive Cancer Network. Esophageal and Esophagogastric Junction Cancers. 2019. Available online: www.nccn.org (accessed on 12 December 2019).

14. Mariette, C.; Dahan, L.; Mornex, F.; Maillard, E.; Thomas, P.A.; Meunier, B.; Boige, V.; Pezet, D.; Robb, W.B.; Le Brun-Ly, V;; et al. Surgery alone versus chemoradiotherapy followed by surgery for stage I and II esophageal cancer: Final analysis of randomized controlled phase III trial FFCD 9901. J. Clin. Oncol. 2014, 32, 2416-2422. [CrossRef] [PubMed]

15. Brown, J.; Lewis, W.G.; Foliaki, A.; Clark, G.W.B.; Blackshaw, G.; Chan, D.S.Y. Colonic Interposition After Adult Oesophagectomy: Systematic Review and Meta-analysis of Conduit Choice and Outcome. J. Gastrointest. Surg. 2018, 22, 1104-1111. [CrossRef] [PubMed]

16. Hulscher, J.B.; Tijssen, J.G.; Obertop, H.; van Lanschot, J.J. Transthoracic versus transhiatal resection for carcinoma of the esophagus: A meta-analysis. Ann. Thorac. Surg. 2001, 72, 306-313. [CrossRef]

17. Hulscher, J.B.; van Sandick, J.W.; de Boer, A.G.; Wijnhoven, B.P.; Tijssen, J.G.; Fockens, P.; Stalmeier, P.F.; ten Kate, F.J.; van Dekken, H.; Obertop, H.; et al. Extended transthoracic resection compared with limited transhiatal resection for adenocarcinoma of the esophagus. N. Engl. J. Med. 2002, 347, 1662-1669. [CrossRef] [PubMed] 
18. Oshikiri, T.; Takiguchi, G.; Miura, S.; Takase, N.; Hasegawa, H.; Yamamoto, M.; Kanaji, S.; Yamashita, K.; Matsuda, Y.; Matsuda, T.; et al. Current status of minimally invasive esophagectomy for esophageal cancer: Is it truly less invasive? Ann. Gastroenterol. Surg. 2019, 3, 138-145. [CrossRef]

19. Yibulayin, W.; Abulizi, S.; Lv, H.; Sun, W. Minimally invasive oesophagectomy versus open esophagectomy for resectable esophageal cancer: A meta-analysis. World J. Surg. Oncol. 2016, 14, 304. [CrossRef]

20. Brierley, R.C.; Gaunt, D.; Metcalfe, C.; Blazeby, J.M.; Blencowe, N.S.; Jepson, M.; Berrisford, R.G.; Avery, K.N.L.; Hollingworth, W.; Rice, C.T.; et al. Laparoscopically assisted versus open oesophagectomy for patients with oesophageal cancer-the Randomised Oesophagectomy: Minimally Invasive or Open (ROMIO) study: Protocol for a randomised controlled trial (RCT). BMJ Open 2019, 9, e030907. [CrossRef]

21. Cunningham, D.; Allum, W.H.; Stenning, S.P.; Thompson, J.N.; Van de Velde, C.J.; Nicolson, M.; Scarffe, J.H.; Lofts, F.J.; Falk, S.J.; Iveson, T.J.; et al. Perioperative chemotherapy versus surgery alone for resectable gastroesophageal cancer. N. Engl. J. Med. 2016, 355, 11-20. [CrossRef]

22. Ychou, M.; Boige, V.; Pignon, J.P.; Conroy, T.; Bouche, O.; Lebreton, G.; Ducourtieux, M.; Bedenne, L.; Fabre, J.M.; Saint-Aubert, B.; et al. Perioperative chemotherapy compared with surgery alone for resectable gastroesophageal adenocarcinoma: An FNCLCC and FFCD multicenter phase III trial. J. Clin. Oncol. 2011, 29, 1715-1721. [CrossRef]

23. Medical Research Council Oesophageal Cancer Working Group. Surgical resection with or without preoperative chemotherapy in oesophageal cancer: A randomised controlled trial. Lancet 2002, 359, 1727-1733. [CrossRef]

24. Allum, W.H.; Stenning, S.P.; Bancewicz, J.; Clark, P.I.; Langley, R.E. Long-term results of a randomized trial of surgery with or without preoperative chemotherapy in esophageal cancer. J. Clin. Oncol. 2009, 27, 5062-5067. [CrossRef] [PubMed]

25. Alderson, D.; Cunningham, D.; Nankivell, M.; Blazeby, J.M.; Griffin, S.M.; Crellin, A.; Grabsch, H.I.; Langer, R.; Pritchard, S.; Okines, A.; et al. Neoadjuvant cisplatin and fluorouracil versus epirubicin, cisplatin, and capecitabine followed by resection in patients with oesophageal adenocarcinoma (UK MRC OE05): An open-label, randomised phase 3 trial. Lancet Oncol. 2017, 18, 1249-1260. [CrossRef]

26. Al-Batran, S.E.; Homann, N.; Pauligk, C.; Goetze, T.O.; Meiler, J.; Kasper, S.; Kopp, H.G.; Mayer, F.; Haag, G.M.; Luley, K.; et al. Perioperative chemotherapy with fluorouracil plus leucovorin, oxaliplatin, and docetaxel versus fluorouracil or capecitabine plus cisplatin and epirubicin for locally advanced, resectable gastric or gastro-oesophageal junction adenocarcinoma (FLOT4): A randomised, phase 2/3 trial. Lancet 2019, 393, 1948-1957. [CrossRef]

27. Van Hagen, P.; Hulshof, M.C.; van Lanschot, J.J.; Steyerberg, E.W.; van Berge Henegouwen, M.I.; Wijnhoven, B.P.; Richel, D.J.; Nieuwenhuijzen, G.A.; Hospers, G.A.; Bonenkamp, J.J.; et al. Preoperative chemoradiotherapy for esophageal or junctional cancer. N. Engl. J. Med. 2012, 366, 2074-2084. [CrossRef] [PubMed]

28. Shapiro, J.; van Lanschot, J.J.B.; Hulshof, M.; van Hagen, P.; van Berge Henegouwen, M.I.; Wijnhoven, B.P.L.; van Laarhoven, H.W.M.; Nieuwenhuijzen, G.A.P.; Hospers, G.A.P.; Bonenkamp, J.J.; et al. Neoadjuvant chemoradiotherapy plus surgery versus surgery alone for oesophageal or junctional cancer (CROSS): Long-term results of a randomised controlled trial. Lancet Oncol. 2015, 16, 1090-1098. [CrossRef]

29. Avendano, C.E.; Flume, P.A.; Silvestri, G.A.; King, L.B.; Reed, C.E. Pulmonary complications after esophagectomy. Ann. Thorac. Surg. 2002, 73, 922-926. [CrossRef]

30. Lin, F.C.; Durkin, A.E.; Ferguson, M.K. Induction therapy does not increase surgical morbidity after esophagectomy for cancer. Ann. Thorac. Surg. 2004, 78, 1783-1789. [CrossRef]

31. Urschel, J.D. Esophagogastrostomy anastomotic leaks complicating esophagectomy: A review. Am. J. Surg. 1995, 169, 634-640. [CrossRef]

32. Walsh, T.N.; Noonan, N.; Hollywood, D.; Kelly, A.; Keeling, N.; Hennessy, T.P. A comparison of multimodal therapy and surgery for esophageal adenocarcinoma. N. Engl. J. Med. 1996, 335, 462-467. [CrossRef]

33. Schulze, B.; Bergis, D.; Balermpas, P.; Trojan, J.; Woeste, G.; Bechstein, W.O.; Rodel, C.; Weiss, C. Neoadjuvant chemoradiation versus perioperative chemotherapy followed by surgery in resectable adenocarcinomas of the esophagogastric junction: A retrospective single center analysis. Oncol. Lett. 2014, 7, 534-540. [CrossRef] [PubMed] 
34. Luu, T.D.; Gaur, P.; Force, S.D.; Staley, C.A.; Mansour, K.A.; Miller, J.I., Jr.; Miller, D.L. Neoadjuvant chemoradiation versus chemotherapy for patients undergoing esophagectomy for esophageal cancer. Ann. Thorac. Surg. 2008, 85, 1217-1223. [CrossRef] [PubMed]

35. Zhao, X.; Ren, Y.; Hu, Y.; Cui, N.; Wang, X.; Cui, Y. Neoadjuvant chemotherapy versus neoadjuvant chemoradiotherapy for cancer of the esophagus or the gastroesophageal junction: A meta-analysis based on clinical trials. PLOS ONE 2018, 13, e0202185. [CrossRef] [PubMed]

36. Deng, H.Y.; Wang, W.P.; Wang, Y.C.; Hu, W.P.; Ni, P.Z.; Lin, Y.D.; Chen, L.Q. Neoadjuvant chemoradiotherapy or chemotherapy? A comprehensive systematic review and meta-analysis of the options for neoadjuvant therapy for treating oesophageal cancer. Eur. J. Cardiothorac. Surg. 2017, 51, 421-431. [CrossRef] [PubMed]

37. Goense, L.; van der Sluis, P.C.; van Rossum, P.S.N.; van der Horst, S.; Meijer, G.J.; Haj Mohammad, N.; van Vulpen, M.; Mook, S.; Ruurda, J.P.; van Hillegersberg, R. Perioperative chemotherapy versus neoadjuvant chemoradiotherapy for esophageal or GEJ adenocarcinoma: A propensity score-matched analysis comparing toxicity, pathologic outcome, and survival. J. Surg. Oncol. 2017, 115, 812-820. [CrossRef]

38. Cooper, J.S.; Guo, M.D.; Herskovic, A.; Macdonald, J.S.; Martenson, J.A., Jr.; Al-Sarraf, M.; Byhardt, R.; Russell, A.H.; Beitler, J.J.; Spencer, S.; et al. Chemoradiotherapy of locally advanced esophageal cancer: Long-term follow-up of a prospective randomized trial (RTOG 85-01). Radiation Therapy Oncology Group. JAMA 1999, 281, 1623-1627. [CrossRef] [PubMed]

39. Pagliarini, R.; Shao, W.; Sellers, W.R. Oncogene addiction: Pathways of therapeutic response, resistance, and road maps toward a cure. EMBO Rep. 2015, 16, 280-296. [CrossRef]

40. Felsher, D.W. Oncogene addiction versus oncogene amnesia: Perhaps more than just a bad habit? Cancer Res. 2008, 68, 3081-3086, discussion 3086. [CrossRef]

41. O’Brien, S.G.; Guilhot, F.; Larson, R.A.; Gathmann, I.; Baccarani, M.; Cervantes, F.; Cornelissen, J.J.; Fischer, T.; Hochhaus, A.; Hughes, T.; et al. Imatinib compared with interferon and low-dose cytarabine for newly diagnosed chronic-phase chronic myeloid leukemia. N. Engl. J. Med. 2003, 348, 994-1004. [CrossRef]

42. Felsher, D.W. Tumor dormancy and oncogene addiction. APMIS 2008, 116, 629-637. [CrossRef]

43. Gravalos, C.; Jimeno, A. HER2 in gastric cancer: A new prognostic factor and a novel therapeutic target. Ann. Oncol. 2008, 19, 1523-1529. [CrossRef] [PubMed]

44. Rowinsky, E.K. The erbB family: Targets for therapeutic development against cancer and therapeutic strategies using monoclonal antibodies and tyrosine kinase inhibitors. Annu. Rev. Med. 2004, 55, $433-457$. [CrossRef]

45. Wilkinson, N.W.; Black, J.D.; Roukhadze, E.; Driscoll, D.; Smiley, S.; Hoshi, H.; Geradts, J.; Javle, M.; Brattain, M. Epidermal growth factor receptor expression correlates with histologic grade in resected esophageal adenocarcinoma. J. Gastrointest. Surg. 2004, 8, 448-453. [CrossRef] [PubMed]

46. Strickler, J.H. EGFR Amplification as a Target in Gastroesophageal Adenocarcinoma: Do Anti-EGFR Therapies Deserve a Second Chance? Cancer Discov. 2018, 8, 679-681. [CrossRef] [PubMed]

47. Bhat, A.A.; Lu, H.; Soutto, M.; Capobianco, A.; Rai, P.; Zaika, A.; El-Rifai, W. Exposure of Barrett's and esophageal adenocarcinoma cells to bile acids activates EGFR-STAT3 signaling axis via induction of APE1. Oncogene 2018, 37, 6011-6024. [CrossRef] [PubMed]

48. Kyrgidis, A.; Kountouras, J.; Zavos, C.; Chatzopoulos, D. New molecular concepts of Barrett's esophagus: Clinical implications and biomarkers. J. Surg. Res. 2005, 125, 189-212. [CrossRef] [PubMed]

49. Avissar, N.E.; Toia, L.; Hu, Y.; Watson, T.J.; Jones, C.; Raymond, D.P.; Matousek, A.; Peters, J.H. Bile acid alone, or in combination with acid, induces CDX2 expression through activation of the epidermal growth factor receptor (EGFR). J. Gastrointest. Surg. 2009, 13, 212-222. [CrossRef]

50. Garcia-Foncillas, J.; Sunakawa, Y.; Aderka, D.; Wainberg, Z.; Ronga, P.; Witzler, P.; Stintzing, S. Distinguishing Features of Cetuximab and Panitumumab in Colorectal Cancer and Other Solid Tumors. Front. Oncol. 2019, 9, 849. [CrossRef]

51. Lordick, F.; Kang, Y.K.; Chung, H.C.; Salman, P.; Oh, S.C.; Bodoky, G.; Kurteva, G.; Volovat, C.; Moiseyenko, V.M.; Gorbunova, V.; et al. Capecitabine and cisplatin with or without cetuximab for patients with previously untreated advanced gastric cancer (EXPAND): A randomised, open-label phase 3 trial. Lancet Oncol. 2013, 14, 490-499. [CrossRef] 
52. Waddell, T.; Chau, I.; Cunningham, D.; Gonzalez, D.; Okines, A.F.; Okines, C.; Wotherspoon, A.; Saffery, C.; Middleton, G.; Wadsley, J.; et al. Epirubicin, oxaliplatin, and capecitabine with or without panitumumab for patients with previously untreated advanced oesophagogastric cancer (REAL3): A randomised, open-label phase 3 trial. Lancet Oncol. 2013, 14, 481-489. [CrossRef]

53. Drenckhan, A.; Grob, T.; Dupree, A.; Dohrmann, T.; Mann, O.; Izbicki, J.R.; Gros, S.J. Esophageal carcinoma cell line with high EGFR polysomy is responsive to gefitinib. Langenbecks Arch. Surg. 2014, 399, 879-888. [CrossRef] [PubMed]

54. Dutton, S.J.; Ferry, D.R.; Blazeby, J.M.; Abbas, H.; Dahle-Smith, A.; Mansoor, W.; Thompson, J.; Harrison, M.; Chatterjee, A.; Falk, S.; et al. Gefitinib for oesophageal cancer progressing after chemotherapy (COG): A phase 3, multicentre, double-blind, placebo-controlled randomised trial. Lancet Oncol. 2014, 15, 894-904. [CrossRef]

55. Petty, R.D.; Dahle-Smith, A.; Stevenson, D.A.J.; Osborne, A.; Massie, D.; Clark, C.; Murray, G.I.; Dutton, S.J.; Roberts, C.; Chong, I.Y.; et al. Gefitinib and EGFR Gene Copy Number Aberrations in Esophageal Cancer. J. Clin. Oncol. 2017, 35, 2279-2287. [CrossRef] [PubMed]

56. Yang, Z.Y.; Shen, W.X.; Hu, X.F.; Zheng, D.Y.; Wu, X.Y.; Huang, Y.F.; Chen, J.Z.; Mao, C.; Tang, J.L. EGFR gene copy number as a predictive biomarker for the treatment of metastatic colorectal cancer with anti-EGFR monoclonal antibodies: A meta-analysis. J. Hematol. Oncol. 2012, 5, 52. [CrossRef] [PubMed]

57. Luber, B.; Deplazes, J.; Keller, G.; Walch, A.; Rauser, S.; Eichmann, M.; Langer, R.; Hofler, H.; Hegewisch-Becker, S.; Folprecht, G.; et al. Biomarker analysis of cetuximab plus oxaliplatin/leucovorin/5-fluorouracil in first-line metastatic gastric and oesophago-gastric junction cancer: Results from a phase II trial of the Arbeitsgemeinschaft Internistische Onkologie (AIO). BMC Cancer 2011, 11, 509. [CrossRef] [PubMed]

58. Maron, S.B.; Alpert, L.; Kwak, H.A.; Lomnicki, S.; Chase, L.; Xu, D.; O’Day, E.; Nagy, R.J.; Lanman, R.B.; Cecchi, F.; et al. Targeted Therapies for Targeted Populations: Anti-EGFR Treatment for EGFR-Amplified Gastroesophageal Adenocarcinoma. Cancer Discov. 2018, 8, 696-713. [CrossRef] [PubMed]

59. Rubin, I.; Yarden, Y. The basic biology of HER2. Ann. Oncol. 2001, 12 (Suppl. S1), S3-S8. [CrossRef]

60. Tai, W.; Mahato, R.; Cheng, K. The role of HER2 in cancer therapy and targeted drug delivery. J. Control. Release 2010, 146, 264-275. [CrossRef]

61. Janser, F.A.; Adams, O.; Butler, V.; Schlafli, A.M.; Dislich, B.; Seiler, C.A.; Kroll, D.; Langer, R.; Tschan, M.P. Her2-Targeted Therapy Induces Autophagy in Esophageal Adenocarcinoma Cells. Int. J. Mol. Sci. 2018, 19, 3069. [CrossRef]

62. Pinto, A.C.; Ades, F.; de Azambuja, E.; Piccart-Gebhart, M. Trastuzumab for patients with HER2 positive breast cancer: Delivery, duration and combination therapies. Breast 2013, 22 (Suppl. S2), S152-S155. [CrossRef]

63. Bang, Y.J.; Van Cutsem, E.; Feyereislova, A.; Chung, H.C.; Shen, L.; Sawaki, A.; Lordick, F.; Ohtsu, A.; Omuro, Y.; Satoh, T.; et al. Trastuzumab in combination with chemotherapy versus chemotherapy alone for treatment of HER2-positive advanced gastric or gastro-oesophageal junction cancer (ToGA): A phase 3, open-label, randomised controlled trial. Lancet 2010, 376, 687-697. [CrossRef]

64. Safran, H.; Winter, K.A.; Wigle, D.A.; DiPetrillo, T.A.; Haddock, M.G.; Hong, T.S.; Leichman, L.P.; Rajdev, L.; Resnick, M.B.; Kachnic, L.A.; et al. Trastuzumab with trimodality treatment for esophageal adenocarcinoma with HER2 overexpression: NRG Oncology/RTOG 1010. J. Clin. Oncol. 2020, 38, 4500. [CrossRef]

65. Agus, D.B.; Gordon, M.S.; Taylor, C.; Natale, R.B.; Karlan, B.; Mendelson, D.S.; Press, M.F.; Allison, D.E.; Sliwkowski, M.X.; Lieberman, G.; et al. Phase I clinical study of pertuzumab, a novel HER dimerization inhibitor, in patients with advanced cancer. J. Clin. Oncol. 2005, 23, 2534-2543. [CrossRef] [PubMed]

66. Nahta, R.; Hung, M.C.; Esteva, F.J. The HER-2-targeting antibodies trastuzumab and pertuzumab synergistically inhibit the survival of breast cancer cells. Cancer Res. 2004, 64, 2343-2346. [CrossRef]

67. Scheuer, W.; Friess, T.; Burtscher, H.; Bossenmaier, B.; Endl, J.; Hasmann, M. Strongly enhanced antitumor activity of trastuzumab and pertuzumab combination treatment on HER2-positive human xenograft tumor models. Cancer Res. 2009, 69, 9330-9336. [CrossRef]

68. Swain, S.M.; Baselga, J.; Kim, S.B.; Ro, J.; Semiglazov, V.; Campone, M.; Ciruelos, E.; Ferrero, J.M.; Schneeweiss, A.; Heeson, S.; et al. Pertuzumab, trastuzumab, and docetaxel in HER2-positive metastatic breast cancer. N. Engl. J. Med. 2015, 372, 724-734. [CrossRef] 
69. Tabernero, J.; Hoff, P.M.; Shen, L.; Ohtsu, A.; Shah, M.A.; Cheng, K.; Song, C.; Wu, H.; Eng-Wong, J.; Kim, K.; et al. Pertuzumab plus trastuzumab and chemotherapy for HER2-positive metastatic gastric or gastro-oesophageal junction cancer (JACOB): Final analysis of a double-blind, randomised, placebo-controlled phase 3 study. Lancet Oncol. 2018, 19, 1372-1384. [CrossRef]

70. Stroes, C.I.; Schokker, S.; Creemers, A.; Molenaar, R.J.; Hulshof, M.; van der Woude, S.O.; Bennink, R.J.; Mathot, R.A.A.; Krishnadath, K.K.; Punt, C.J.A.; et al. Phase II Feasibility and Biomarker Study of Neoadjuvant Trastuzumab and Pertuzumab With Chemoradiotherapy for Resectable Human Epidermal Growth Factor Receptor 2-Positive Esophageal Adenocarcinoma: TRAP Study. J. Clin. Oncol. 2020, 38, 462-471. [CrossRef] [PubMed]

71. Sanchez-Vega, F.; Hechtman, J.F.; Castel, P.; Ku, G.Y.; Tuvy, Y.; Won, H.; Fong, C.J.; Bouvier, N.; Nanjangud, G.J.; Soong, J.; et al. EGFR and MET Amplifications Determine Response to HER2 Inhibition in ERBB2-Amplified Esophagogastric Cancer. Cancer Discov. 2019, 9, 199-209. [CrossRef]

72. Klagsbrun, M.; D'Amore, P.A. Vascular endothelial growth factor and its receptors. Cytokine Growth Factor Rev. 1996, 7, 259-270. [CrossRef]

73. Inoue, M.; Hager, J.H.; Ferrara, N.; Gerber, H.P.; Hanahan, D. VEGF-A has a critical, nonredundant role in angiogenic switching and pancreatic beta cell carcinogenesis. Cancer Cell 2002, 1, 193-202. [CrossRef]

74. Kerbel, R.S. Tumor angiogenesis. N. Engl. J. Med. 2008, 358, 2039-2049. [CrossRef] [PubMed]

75. Kleespies, A.; Bruns, C.J.; Jauch, K.W. Clinical significance of VEGF-A, -C and -D expression in esophageal malignancies. Onkologie 2005, 28, 281-288. [CrossRef] [PubMed]

76. Burnat, G.; Rau, T.; Elshimi, E.; Hahn, E.G.; Konturek, P.C. Bile acids induce overexpression of homeobox gene CDX-2 and vascular endothelial growth factor (VEGF) in human Barrett's esophageal mucosa and adenocarcinoma cell line. Scand. J. Gastroenterol. 2007, 42, 1460-1465. [CrossRef]

77. Hurwitz, H.; Fehrenbacher, L.; Novotny, W.; Cartwright, T.; Hainsworth, J.; Heim, W.; Berlin, J.; Baron, A.; Griffing, S.; Holmgren, E.; et al. Bevacizumab plus irinotecan, fluorouracil, and leucovorin for metastatic colorectal cancer. N. Engl. J. Med. 2004, 350, 2335-2342. [CrossRef]

78. Ohtsu, A.; Shah, M.A.; Van Cutsem, E.; Rha, S.Y.; Sawaki, A.; Park, S.R.; Lim, H.Y.; Yamada, Y.; Wu, J.; Langer, B.; et al. Bevacizumab in combination with chemotherapy as first-line therapy in advanced gastric cancer: A randomized, double-blind, placebo-controlled phase III study. J. Clin. Oncol. 2011, 29, 3968-3976. [CrossRef] [PubMed]

79. Cunningham, D.; Stenning, S.P.; Smyth, E.C.; Okines, A.F.; Allum, W.H.; Rowley, S.; Stevenson, L.; Grabsch, H.I.; Alderson, D.; Crosby, T.; et al. Peri-operative chemotherapy with or without bevacizumab in operable oesophagogastric adenocarcinoma (UK Medical Research Council ST03): Primary analysis results of a multicentre, open-label, randomised phase 2-3 trial. Lancet Oncol. 2017, 18, 357-370. [CrossRef]

80. Spratlin, J.L.; Cohen, R.B.; Eadens, M.; Gore, L.; Camidge, D.R.; Diab, S.; Leong, S.; O’Bryant, C.; Chow, L.Q.; Serkova, N.J.; et al. Phase I pharmacologic and biologic study of ramucirumab (IMC-1121B), a fully human immunoglobulin G1 monoclonal antibody targeting the vascular endothelial growth factor receptor- 2 . J. Clin. Oncol. 2010, 28, 780-787. [CrossRef]

81. Fuchs, C.S.; Tomasek, J.; Yong, C.J.; Dumitru, F.; Passalacqua, R.; Goswami, C.; Safran, H.; Dos Santos, L.V.; Aprile, G.; Ferry, D.R.; et al. Ramucirumab monotherapy for previously treated advanced gastric or gastro-oesophageal junction adenocarcinoma (REGARD): An international, randomised, multicentre, placebo-controlled, phase 3 trial. Lancet 2014, 383, 31-39. [CrossRef]

82. Wilke, H.; Muro, K.; Van Cutsem, E.; Oh, S.C.; Bodoky, G.; Shimada, Y.; Hironaka, S.; Sugimoto, N.; Lipatov, O.; Kim, T.Y.; et al. Ramucirumab plus paclitaxel versus placebo plus paclitaxel in patients with previously treated advanced gastric or gastro-oesophageal junction adenocarcinoma (RAINBOW): A double-blind, randomised phase 3 trial. Lancet Oncol. 2014, 15, 1224-1235. [CrossRef]

83. Casak, S.J.; Fashoyin-Aje, I.; Lemery, S.J.; Zhang, L.; Jin, R.; Li, H.; Zhao, L.; Zhao, H.; Zhang, H.; Chen, H.; et al. FDA Approval Summary: Ramucirumab for Gastric Cancer. Clin. Cancer Res. 2015, 21, 3372-3376. [CrossRef] [PubMed]

84. Fuchs, C.S.; Shitara, K.; Di Bartolomeo, M.; Lonardi, S.; Al-Batran, S.E.; Van Cutsem, E.; Ilson, D.H.; Alsina, M.; Chau, I.; Lacy, J.; et al. Ramucirumab with cisplatin and fluoropyrimidine as first-line therapy in patients with metastatic gastric or junctional adenocarcinoma (RAINFALL): A double-blind, randomised, placebo-controlled, phase 3 trial. Lancet Oncol. 2019, 20, 420-435. [CrossRef] 
85. Li, J.; Qin, S.; Xu, J.; Xiong, J.; Wu, C.; Bai, Y.; Liu, W.; Tong, J.; Liu, Y.; Xu, R.; et al. Randomized, Double-Blind, Placebo-Controlled Phase III Trial of Apatinib in Patients With Chemotherapy-Refractory Advanced or Metastatic Adenocarcinoma of the Stomach or Gastroesophageal Junction. J. Clin. Oncol. 2016, 34, 1448-1454. [CrossRef] [PubMed]

86. Xu, Z.; Hu, C.; Chen, S.; Zhang, C.; Yu, J.; Wang, X.; Lv, H.; Cheng, X. Apatinib enhances chemosensitivity of gastric cancer to paclitaxel and 5-fluorouracil. Cancer Manag. Res. 2019, 11, 4905-4915. [CrossRef] [PubMed]

87. Cecchi, F.; Rabe, D.C.; Bottaro, D.P. Targeting the HGF/Met signaling pathway in cancer therapy. Expert Opin. Ther. Targets 2012, 16, 553-572. [CrossRef] [PubMed]

88. Santoro, A.; Rimassa, L.; Borbath, I.; Daniele, B.; Salvagni, S.; Van Laethem, J.L.; Van Vlierberghe, H.; Trojan, J.; Kolligs, F.T.; Weiss, A.; et al. Tivantinib for second-line treatment of advanced hepatocellular carcinoma: A randomised, placebo-controlled phase 2 study. Lancet Oncol. 2013, 14, 55-63. [CrossRef]

89. Appleman, L.J. MET signaling pathway: A rational target for cancer therapy. J. Clin. Oncol. 2011, 29, 4837-4838. [CrossRef]

90. Creemers, A.; Ebbing, E.A.; Pelgrim, T.C.; Lagarde, S.M.; van Etten-Jamaludin, F.S.; van Berge Henegouwen, M.I.; Hulshof, M.; Krishnadath, K.K.; Meijer, S.L.; Bijlsma, M.F.; et al. A systematic review and meta-analysis of prognostic biomarkers in resectable esophageal adenocarcinomas. Sci. Rep. 2018, 8, 13281. [CrossRef]

91. Ren, J.L.; Wu, H.F.; Wang, W.J.; Hu, G.M.; Gu, B.; Zhang, M.; Wang, Y.X. C-Met as a potential novel prognostic marker in squamous cell carcinoma and adenocarcinoma of esophagus: Evidence from a meta-analysis. Panminerva Med. 2017, 59, 97-106. [CrossRef]

92. Catenacci, D.V.T.; Tebbutt, N.C.; Davidenko, I.; Murad, A.M.; Al-Batran, S.E.; Ilson, D.H.; Tjulandin, S.; Gotovkin, E.; Karaszewska, B.; Bondarenko, I.; et al. Rilotumumab plus epirubicin, cisplatin, and capecitabine as first-line therapy in advanced MET-positive gastric or gastro-oesophageal junction cancer (RILOMET-1): A randomised, double-blind, placebo-controlled, phase 3 trial. Lancet Oncol. 2017, 18, 1467-1482. [CrossRef]

93. Shah, M.A.; Bang, Y.J.; Lordick, F.; Alsina, M.; Chen, M.; Hack, S.P.; Bruey, J.M.; Smith, D.; McCaffery, I.; Shames, D.S.; et al. Effect of Fluorouracil, Leucovorin, and Oxaliplatin With or Without Onartuzumab in HER2-Negative, MET-Positive Gastroesophageal Adenocarcinoma: The METGastric Randomized Clinical Trial. JAMA Oncol. 2017, 3, 620-627. [CrossRef] [PubMed]

94. Munshi, N.; Jeay, S.; Li, Y.; Chen, C.R.; France, D.S.; Ashwell, M.A.; Hill, J.; Moussa, M.M.; Leggett, D.S.; $\mathrm{Li}, \mathrm{C} . J$. ARQ 197, a novel and selective inhibitor of the human c-Met receptor tyrosine kinase with antitumor activity. Mol. Cancer Ther. 2017, 9, 1544-1553. [CrossRef] [PubMed]

95. Pant, S.; Patel, M.; Kurkjian, C.; Hemphill, B.; Flores, M.; Thompson, D.; Bendell, J. A Phase II Study of the c-Met Inhibitor Tivantinib in Combination with FOLFOX for the Treatment of Patients with Previously Untreated Metastatic Adenocarcinoma of the Distal Esophagus, Gastroesophageal Junction, or Stomach. Cancer Investig. 2017, 35, 463-472. [CrossRef] [PubMed]

96. Korc, M.; Friesel, R.E. The role of fibroblast growth factors in tumor growth. Curr. Cancer Drug. Targets 2009, 9, 639-651. [CrossRef] [PubMed]

97. Touat, M.; Ileana, E.; Postel-Vinay, S.; Andre, F.; Soria, J.C. Targeting FGFR Signaling in Cancer. Clin. Cancer Res. 2015, 21, 2684-2694. [CrossRef] [PubMed]

98. Su, X.; Zhan, P.; Gavine, P.R.; Morgan, S.; Womack, C.; Ni, X.; Shen, D.; Bang, Y.J.; Im, S.A.; Ho Kim, W.; et al. FGFR2 amplification has prognostic significance in gastric cancer: Results from a large international multicentre study. Br. J. Cancer 2014, 110, 967-975. [CrossRef]

99. Catenacci, D.V.T.; Rasco, D.; Lee, J.; Rha, S.Y.; Lee, K.W.; Bang, Y.J.; Bendell, J.; Enzinger, P.; Marina, N.; Xiang, H.; et al. Phase I Escalation and Expansion Study of Bemarituzumab (FPA144) in Patients With Advanced Solid Tumors and FGFR2b-Selected Gastroesophageal Adenocarcinoma. J. Clin. Oncol. 2020, JCO1901834. [CrossRef]

100. Catenacci, D.V.T.; Rha, S.Y.; Bang, Y.J.; Wainberg, Z.A.; Choa, J.; Lee, K.W.; Korn, W.M.; Kim, Y.H.; Song, E.K.; Chiu, C.-F.; et al. Updated antitumor activity and safety of FPA144, an ADCC-enhanced, FGFR2b isoform-specific monoclonal antibody, in patients with FGFR2b+ gastric cancer. J. Clin. Oncol. 2017, 35, 4067. [CrossRef]

101. Xie, L.; Su, X.; Zhang, L.; Yin, X.; Tang, L.; Zhang, X.; Xu, Y.; Gao, Z.; Liu, K.; Zhou, M.; et al. FGFR2 gene amplification in gastric cancer predicts sensitivity to the selective FGFR inhibitor AZD4547. Clin. Cancer Res. 2013, 19, 2572-2583. [CrossRef] 
102. Van Cutsem, E.; Bang, Y.J.; Mansoor, W.; Petty, R.D.; Chao, Y.; Cunningham, D.; Ferry, D.R.; Smith, N.R.; Frewer, P.; Ratnayake, J.; et al. A randomized, open-label study of the efficacy and safety of AZD4547 monotherapy versus paclitaxel for the treatment of advanced gastric adenocarcinoma with FGFR2 polysomy or gene amplification. Ann. Oncol. 2017, 28, 1316-1324. [CrossRef]

103. Pepper, M.S.; Mandriota, S.J.; Jeltsch, M.; Kumar, V.; Alitalo, K. Vascular endothelial growth factor (VEGF)-C synergizes with basic fibroblast growth factor and VEGF in the induction of angiogenesis in vitro and alters endothelial cell extracellular proteolytic activity. J. Cell Physiol. 1998, 177, 439-452. [CrossRef]

104. Kopetz, S.; Hoff, P.M.; Morris, J.S.; Wolff, R.A.; Eng, C.; Glover, K.Y.; Adinin, R.; Overman, M.J.; Valero, V.; Wen, S.; et al. Phase II trial of infusional fluorouracil, irinotecan, and bevacizumab for metastatic colorectal cancer: Efficacy and circulating angiogenic biomarkers associated with therapeutic resistance. J. Clin. Oncol. 2010, 28, 453-459. [CrossRef] [PubMed]

105. Golfmann, K.; Meder, L.; Koker, M.; Volz, C.; Borchmann, S.; Tharun, L.; Dietlein, F.; Malchers, F.; Florin, A.; Buttner, R.; et al. Synergistic anti-angiogenic treatment effects by dual FGFR1 and VEGFR1 inhibition in FGFR1-amplified breast cancer. Oncogene 2018, 37, 5682-5693. [CrossRef] [PubMed]

106. Li, D.; Xie, K.; Zhang, L.; Yao, X.; Li, H.; Xu, Q.; Wang, X.; Jiang, J.; Fang, J. Dual blockade of vascular endothelial growth factor (VEGF) and basic fibroblast growth factor (FGF-2) exhibits potent anti-angiogenic effects. Cancer Lett. 2016, 377, 164-173. [CrossRef]

107. Schmelzle, T.; Hall, M.N. TOR, a central controller of cell growth. Cell 2000, 103, 253-262. [CrossRef]

108. Hay, N.; Sonenberg, N. Upstream and downstream of mTOR. Genes Dev. 2004, 18, 1926-1945. [CrossRef]

109. Nishikawa, T.; Takaoka, M.; Ohara, T.; Tomono, Y.; Hao, H.; Bao, X.; Fukazawa, T.; Wang, Z.; Sakurama, K.; Fujiwara, Y.; et al. Antiproliferative effect of a novel mTOR inhibitor temsirolimus contributes to the prolonged survival of orthotopic esophageal cancer-bearing mice. Cancer Biol. Ther. 2013, 14, 230-236. [CrossRef]

110. Baselga, J.; Campone, M.; Piccart, M.; Burris, H.A., 3rd; Rugo, H.S.; Sahmoud, T.; Noguchi, S.; Gnant, M.; Pritchard, K.I.; Lebrun, F.; et al. Everolimus in postmenopausal hormone-receptor-positive advanced breast cancer. N. Engl. J. Med. 2012, 366, 520-529. [CrossRef]

111. Motzer, R.J.; Escudier, B.; Oudard, S.; Hutson, T.E.; Porta, C.; Bracarda, S.; Grunwald, V.; Thompson, J.A.; Figlin, R.A.; Hollaender, N.; et al. Efficacy of everolimus in advanced renal cell carcinoma: A double-blind, randomised, placebo-controlled phase III trial. Lancet 2008, 372, 449-456. [CrossRef]

112. Taguchi, F.; Kodera, Y.; Katanasaka, Y.; Yanagihara, K.; Tamura, T.; Koizumi, F. Efficacy of RAD001 (everolimus) against advanced gastric cancer with peritoneal dissemination. Investig. New Drugs 2011, 29, 1198-1205. [CrossRef]

113. Ohtsu, A.; Ajani, J.A.; Bai, Y.X.; Bang, Y.J.; Chung, H.C.; Pan, H.M.; Sahmoud, T.; Shen, L.; Yeh, K.H.; Chin, K.; et al. Everolimus for previously treated advanced gastric cancer: Results of the randomized, double-blind, phase III GRANITE-1 study. J. Clin. Oncol. 2013, 31, 3935-3943. [CrossRef] [PubMed]

114. Wainberg, Z.A.; Soares, H.P.; Patel, R.; DiCarlo, B.; Park, D.J.; Liem, A.; Wang, H.J.; Yonemoto, L.; Martinez, D.; Laux, I.; et al. Phase II trial of everolimus in patients with refractory metastatic adenocarcinoma of the esophagus, gastroesophageal junction and stomach: Possible role for predictive biomarkers. Cancer Chemother. Pharmacol. 2015, 76, 61-67. [CrossRef] [PubMed]

115. Meyer, P.; Prodromou, C.; Hu, B.; Vaughan, C.; Roe, S.M.; Panaretou, B.; Piper, P.W.; Pearl, L.H. Structural and functional analysis of the middle segment of hsp90: Implications for ATP hydrolysis and client protein and cochaperone interactions. Mol. Cell 2003, 11, 647-658. [CrossRef]

116. Wu, X.; Wanders, A.; Wardega, P.; Tinge, B.; Gedda, L.; Bergstrom, S.; Sooman, L.; Gullbo, J.; Bergqvist, M.; Hesselius, P.; et al. Hsp90 is expressed and represents a therapeutic target in human oesophageal cancer using the inhibitor 17-allylamino-17-demethoxygeldanamycin. Br. J. Cancer 2009, 100, 334-343. [CrossRef]

117. Neckers, L.; Ivy, S.P. Heat shock protein 90. Curr. Opin. Oncol. 2003, 15, 419-424. [CrossRef] [PubMed]

118. Schneider, C.; Sepp-Lorenzino, L.; Nimmesgern, E.; Ouerfelli, O.; Danishefsky, S.; Rosen, N.; Hartl, F.U. Pharmacologic shifting of a balance between protein refolding and degradation mediated by Hsp90. Proc. Natl. Acad. Sci. USA 1996, 93, 14536-14541. [CrossRef]

119. Slotta-Huspenina, J.; Becker, K.F.; Feith, M.; Walch, A.; Langer, R. Heat Shock Protein 90 (HSP90) and Her2 in Adenocarcinomas of the Esophagus. Cancers (Basel) 2014, 6, 1382-1393. [CrossRef] 
120. Lang, S.A.; Klein, D.; Moser, C.; Gaumann, A.; Glockzin, G.; Dahlke, M.H.; Dietmaier, W.; Bolder, U.; Schlitt, H.J.; Geissler, E.K.; et al. Inhibition of heat shock protein 90 impairs epidermal growth factor-mediated signaling in gastric cancer cells and reduces tumor growth and vascularization in vivo. Mol. Cancer Ther. 2007, 6, 1123-1132. [CrossRef]

121. Wainberg, Z.A.; Anghel, A.; Rogers, A.M.; Desai, A.J.; Kalous, O.; Conklin, D.; Ayala, R.; O’Brien, N.A.; Quadt, C.; Akimov, M.; et al. Inhibition of HSP90 with AUY922 induces synergy in HER2-amplified trastuzumab-resistant breast and gastric cancer. Mol. Cancer Ther. 2013, 12, 509-519. [CrossRef]

122. Park, K.S.; Hong, Y.S.; Choi, J.; Yoon, S.; Kang, J.; Kim, D.; Lee, K.P.; Im, H.S.; Lee, C.H.; Seo, S.; et al. HSP90 inhibitor, AUY922, debilitates intrinsic and acquired lapatinib-resistant HER2-positive gastric cancer cells. BMB Rep. 2018, 51, 660-665. [CrossRef]

123. Kong, A.; Rea, D.; Ahmed, S.; Beck, J.T.; Lopez Lopez, R.; Biganzoli, L.; Armstrong, A.C.; Aglietta, M.; Alba, E.; Campone, M.; et al. Phase 1B/2 study of the HSP90 inhibitor AUY922 plus trastuzumab in metastatic HER2-positive breast cancer patients who have progressed on trastuzumab-based regimen. Oncotarget 2016, 7, 37680-37692. [CrossRef] [PubMed]

124. Kosovec, J.E.; Zaidi, A.H.; Kelly, L.A.; Rotoloni, C.L.; Vytlacil, C.; DiCarlo, C.; Matsui, D.; Komatsu, Y.; Boyd, N.H.; Omstead, A.; et al. Preclinical Study of AUY922, a Novel Hsp90 Inhibitor, in the Treatment of Esophageal Adenocarcinoma. Ann. Surg. 2016, 264, 297-304. [CrossRef] [PubMed]

125. Dar, A.A.; Zaika, A.; Piazuelo, M.B.; Correa, P.; Koyama, T.; Belkhiri, A.; Washington, K.; Castells, A.; Pera, M.; El-Rifai, W. Frequent overexpression of Aurora Kinase A in upper gastrointestinal adenocarcinomas correlates with potent antiapoptotic functions. Cancer 2008, 112, 1688-1698. [CrossRef] [PubMed]

126. Sankaran, S.; Crone, D.E.; Palazzo, R.E.; Parvin, J.D. Aurora-A kinase regulates breast cancer associated gene 1 inhibition of centrosome-dependent microtubule nucleation. Cancer Res. 2007, 67, 11186-11194. [CrossRef] [PubMed]

127. Yang, G.; Chang, B.; Yang, F.; Guo, X.; Cai, K.Q.; Xiao, X.S.; Wang, H.; Sen, S.; Hung, M.C.; Mills, G.B.; et al. Aurora kinase A promotes ovarian tumorigenesis through dysregulation of the cell cycle and suppression of BRCA2. Clin. Cancer Res. 2010, 16, 3171-3181. [CrossRef]

128. Sourisseau, T.; Maniotis, D.; McCarthy, A.; Tang, C.; Lord, C.J.; Ashworth, A.; Linardopoulos, S. Aurora-A expressing tumour cells are deficient for homology-directed DNA double strand-break repair and sensitive to PARP inhibition. EMBO Mol. Med. 2010, 2, 130-142. [CrossRef]

129. Dar, A.A.; Belkhiri, A.; Ecsedy, J.; Zaika, A.; El-Rifai, W. Aurora kinase A inhibition leads to p73-dependent apoptosis in p53-deficient cancer cells. Cancer Res. 2008, 68, 8998-9004. [CrossRef]

130. Katayama, H.; Sasai, K.; Kawai, H.; Yuan, Z.M.; Bondaruk, J.; Suzuki, F.; Fujii, S.; Arlinghaus, R.B.; Czerniak, B.A.; Sen, S. Phosphorylation by aurora kinase A induces Mdm2-mediated destabilization and inhibition of p53. Nat. Genet. 2004, 36, 55-62. [CrossRef]

131. Liu, Q.; Kaneko, S.; Yang, L.; Feldman, R.I.; Nicosia, S.V.; Chen, J.; Cheng, J.Q. Aurora-A abrogation of p53 DNA binding and transactivation activity by phosphorylation of serine 215. J. Biol. Chem. 2004, 279, 52175-52182. [CrossRef]

132. Dar, A.A.; Belkhiri, A.; El-Rifai, W. The aurora kinase A regulates GSK-3beta in gastric cancer cells. Oncogene 2009, 28, 866-875. [CrossRef]

133. Katsha, A.; Soutto, M.; Sehdev, V.; Peng, D.; Washington, M.K.; Piazuelo, M.B.; Tantawy, M.N.; Manning, H.C.; Lu, P.; Shyr, Y.; et al. Aurora kinase A promotes inflammation and tumorigenesis in mice and human gastric neoplasia. Gastroenterology 2013, 145, 1312-1322.e8. [CrossRef] [PubMed]

134. Schneider, P.M.; Stoeltzing, O.; Roth, J.A.; Hoelscher, A.H.; Wegerer, S.; Mizumoto, S.; Becker, K.; Dittler, H.J.; Fink, U.; Siewert, J.R. P53 mutational status improves estimation of prognosis in patients with curatively resected adenocarcinoma in Barrett's esophagus. Clin. Cancer Res. 2000, 6, 3153-3158. [PubMed]

135. Wang-Bishop, L.; Chen, Z.; Gomaa, A.; Lockhart, A.C.; Salaria, S.; Wang, J.; Lewis, K.B.; Ecsedy, J.; Washington, K.; Beauchamp, R.D.; et al. Inhibition of AURKA Reduces Proliferation and Survival of Gastrointestinal Cancer Cells With Activated KRAS by Preventing Activation of RPS6KB1. Gastroenterology 2019, 156, 662-675.e667. [CrossRef] [PubMed]

136. Gorgun, G.; Calabrese, E.; Hideshima, T.; Ecsedy, J.; Perrone, G.; Mani, M.; Ikeda, H.; Bianchi, G.; Hu, Y.; Cirstea, D.; et al. A novel Aurora-A kinase inhibitor MLN8237 induces cytotoxicity and cell-cycle arrest in multiple myeloma. Blood 2010, 115, 5202-5213. [CrossRef] 
137. Sehdev, V.; Peng, D.; Soutto, M.; Washington, M.K.; Revetta, F.; Ecsedy, J.; Zaika, A.; Rau, T.T.; Schneider-Stock, R.; Belkhiri, A.; et al. The aurora kinase A inhibitor MLN8237 enhances cisplatin-induced cell death in esophageal adenocarcinoma cells. Mol. Cancer Ther. 2012, 11, 763-774. [CrossRef] [PubMed]

138. Sehdev, V.; Katsha, A.; Ecsedy, J.; Zaika, A.; Belkhiri, A.; El-Rifai, W. The combination of alisertib, an investigational Aurora kinase A inhibitor, and docetaxel promotes cell death and reduces tumor growth in preclinical cell models of upper gastrointestinal adenocarcinomas. Cancer 2013, 119, 904-914. [CrossRef] [PubMed]

139. Melichar, B.; Adenis, A.; Lockhart, A.C.; Bennouna, J.; Dees, E.C.; Kayaleh, O.; Obermannova, R.; DeMichele, A.; Zatloukal, P.; Zhang, B.; et al. Safety and activity of alisertib, an investigational aurora kinase A inhibitor, in patients with breast cancer, small-cell lung cancer, non-small-cell lung cancer, head and neck squamous-cell carcinoma, and gastro-oesophageal adenocarcinoma: A five-arm phase 2 study. Lancet Oncol. 2015, 16, 395-405. [CrossRef]

140. Zhu, C.; Wei, Y.; Wei, X. AXL receptor tyrosine kinase as a promising anti-cancer approach: Functions, molecular mechanisms and clinical applications. Mol. Cancer 2019, 18, 153. [CrossRef]

141. Maacha, S.; Hong, J.; von Lersner, A.; Zijlstra, A.; Belkhiri, A. AXL Mediates Esophageal Adenocarcinoma Cell Invasion through Regulation of Extracellular Acidification and Lysosome Trafficking. Neoplasia 2018, 20, 1008-1022. [CrossRef]

142. Hector, A.; Montgomery, E.A.; Karikari, C.; Canto, M.; Dunbar, K.B.; Wang, J.S.; Feldmann, G.; Hong, S.M.; Haffner, M.C.; Meeker, A.K.; et al. The Axl receptor tyrosine kinase is an adverse prognostic factor and a therapeutic target in esophageal adenocarcinoma. Cancer Biol. Ther. 2010, 10, 1009-1018. [CrossRef]

143. Hong, J.; Peng, D.; Chen, Z.; Sehdev, V.; Belkhiri, A. ABL regulation by AXL promotes cisplatin resistance in esophageal cancer. Cancer Res. 2013, 73, 331-340. [CrossRef]

144. Hong, J.; Maacha, S.; Belkhiri, A. Transcriptional upregulation of c-MYC by AXL confers epirubicin resistance in esophageal adenocarcinoma. Mol. Oncol. 2018, 12, 2191-2208. [CrossRef] [PubMed]

145. Zhang, Z.; Lee, J.C.; Lin, L.; Olivas, V.; Au, V.; LaFramboise, T.; Abdel-Rahman, M.; Wang, X.; Levine, A.D.; Rho, J.K.; et al. Activation of the AXL kinase causes resistance to EGFR-targeted therapy in lung cancer. Nat. Genet. 2012, 44, 852-860. [CrossRef]

146. Rho, J.K.; Choi, Y.J.; Kim, S.Y.; Kim, T.W.; Choi, E.K.; Yoon, S.J.; Park, B.M.; Park, E.; Bae, J.H.; Choi, C.M.; et al. MET and AXL inhibitor NPS-1034 exerts efficacy against lung cancer cells resistant to EGFR kinase inhibitors because of MET or AXL activation. Cancer Res. 2014, 74, 253-262. [CrossRef] [PubMed]

147. Lee, H.T.; Lee, S.H.; Heo, Y.S. Molecular Interactions of Antibody Drugs Targeting PD-1, PD-L1, and CTLA-4 in Immuno-Oncology. Molecules 2019, 24, 1190. [CrossRef] [PubMed]

148. Wolchok, J.D.; Chan, T.A. Cancer: Antitumour immunity gets a boost. Nature 2014, 515, 496-498. [CrossRef] [PubMed]

149. Rho, J.K.; Choi, Y.J.; Kim, S.Y.; Kim, T.W.; Choi, E.K.; Yoon, S.J.; Park, B.M.; Park, E.; Bae, J.H.; Choi, C.M.; et al. Distinct Cellular Mechanisms Underlie Anti-CTLA-4 and Anti-PD-1 Checkpoint Blockade. Cell 2017, 170, 1120-1133.e1117. [CrossRef]

150. Le, D.T.; Durham, J.N.; Smith, K.N.; Wang, H.; Bartlett, B.R.; Aulakh, L.K.; Lu, S.; Kemberling, H.; Wilt, C.; Luber, B.S.; et al. Mismatch repair deficiency predicts response of solid tumors to PD-1 blockade. Science 2017, 357, 409-413. [CrossRef] [PubMed]

151. Le, D.T.; Uram, J.N.; Wang, H.; Bartlett, B.R.; Kemberling, H.; Eyring, A.D.; Skora, A.D.; Luber, B.S.; Azad, N.S.; Laheru, D.; et al. PD-1 Blockade in Tumors with Mismatch-Repair Deficiency. N. Engl. J. Med. 2015, 372, 2509-2520. [CrossRef] [PubMed]

152. Helwick, C. KEYNOTE-062: Pembrolizumab Is a New First-Line Option in Gastric/Gastroesophageal Junction Cancer. 2019. Available online: https://www.ascopost.com/issues/june-25-2019/keynote-062pembrolizumab-in-gastricgej-cancer/\#: \{\}:text=KEYNOTE\%2D062\%20was\%20a\%20phase,cisplatin\% 20and\%20fluorouracil\%20or\%20capecitabine) (accessed on 26 June 2020).

153. Kang, Y.K.; Boku, N.; Satoh, T.; Ryu, M.H.; Chao, Y.; Kato, K.; Chung, H.C.; Chen, J.S.; Muro, K.; Kang, W.K.; et al. Nivolumab in patients with advanced gastric or gastro-oesophageal junction cancer refractory to, or intolerant of, at least two previous chemotherapy regimens (ONO-4538-12, ATTRACTION-2): A randomised, double-blind, placebo-controlled, phase 3 trial. Lancet 2017, 390, 2461-2471. [CrossRef] 
154. Moehler, M.; Shitara, K.; Garrido, M.; Salman, P.; Shen, L.; Wyrwicz, L.; Yamaguchi, K.; Skoczylas, T.; Campos Bragagnoli, A.; Lui, T.; et al. Nivolumab (nivo) plus chemotherapy (chemo) versus chemo as first-line (1L) treatment for advanced gastric cancer/gastroesophageal junction cancer (GC/GEJC)/esophageal adenocarcinoma (EAC): First results of the CheckMate 649 study. Ann. Oncol. 2020, 31, S1191. [CrossRef]

155. Antonia, S.J.; Lopez-Martin, J.A.; Bendell, J.; Ott, P.A.; Taylor, M.; Eder, J.P.; Jager, D.; Pietanza, M.C.; Le, D.T.; de Braud, F.; et al. Nivolumab alone and nivolumab plus ipilimumab in recurrent small-cell lung cancer (CheckMate 032): A multicentre, open-label, phase 1/2 trial. Lancet Oncol. 2016, 17, 883-895. [CrossRef] [PubMed]

156. Overman, M.J.; Lonardi, S.; Wong, K.Y.M.; Lenz, H.J.; Gelsomino, F.; Aglietta, M.; Morse, M.A.; Van Cutsem, E.; McDermott, R.; Hill, A.; et al. Durable Clinical Benefit With Nivolumab Plus Ipilimumab in DNA Mismatch Repair-Deficient/Microsatellite Instability-High Metastatic Colorectal Cancer. J. Clin. Oncol. 2018, 36, 773-779. [CrossRef] [PubMed]

157. Larkin, J.; Chiarion-Sileni, V.; Gonzalez, R.; Grob, J.J.; Cowey, C.L.; Lao, C.D.; Schadendorf, D.; Dummer, R.; Smylie, M.; Rutkowski, P.; et al. Combined Nivolumab and Ipilimumab or Monotherapy in Untreated Melanoma. N. Engl. J. Med. 2015, 373, 23-34. [CrossRef] [PubMed]

158. Janjigian, Y.Y.; Bendell, J.; Calvo, E.; Kim, J.W.; Ascierto, P.A.; Sharma, P.; Ott, P.A.; Peltola, K.; Jaeger, D.; Evans, J.; et al. CheckMate-032 Study: Efficacy and Safety of Nivolumab and Nivolumab Plus Ipilimumab in Patients With Metastatic Esophagogastric Cancer. J. Clin. Oncol. 2018, 36, 2836-2844. [CrossRef]

Publisher's Note: MDPI stays neutral with regard to jurisdictional claims in published maps and institutional affiliations. 